\title{
Abortion and Crime: Unwanted Children and Out-of-Wedlock Births
}

\author{
John R. Lott, Jr. \\ School of Law \\ Yale University \\ New Haven, CT 06511 \\ and \\ John Whitley \\ School of Economics \\ University of Adelaide \\ Adelaide, South Australia \\ Australia
}

February 27, 2001

Revised

May 15, 2001

* We would like to thank Ian Ayres, Richard Epstein, Ed Glaeser, Teb Marvell, David Murray, Sam Peltzman, Florenz Plassman, Eric Posner, Mark Ramseyer, and Bob Reed as well as participants at the American Law and Economics Association meetings for helpful comments. 


\begin{abstract}
Abortion may prevent the birth of "unwanted" children, who would have relatively small investments in human capital and a higher probability of crime. On the other hand, some research suggests that legalizing abortion increases out-of-wedlock births and single parent families, which implies the opposite impact on investments in human capital and thus crime. The question is: what is the net impact? We find evidence that legalizing abortion increased murder rates by around about 0.5 to 7 percent. Previous estimates are shown to suffer from not directly linking the cohorts who are committing crime with whether they had been born before or after abortion was legal.
\end{abstract}

JEL Classification Numbers: K4, D13, H11 


\section{Introduction}

With violent crime rates dropping by 31 percent from their peak in 1991 to 1999 and murder rates declining by 42 percent, many explanations have been offered. This drop is all the more interesting since it occurred while some academics had predicted the rise of "super predators" and an explosion of crime. ${ }^{1}$ In the debate, many plausible explanations for this decline have been advanced, such as: increased arrest and conviction rates, longer prison sentences, "broken windows" or "problem orientated" police policies, the ending of the crack epidemic, a strong economy, right-to-carry concealed handgun laws, and legalizing abortion during the early 1970s. ${ }^{2}$ Generally, all these explanations could be simultaneously true. Most scholars agree that the crime reduction must be due to a range of factors, though they disagree on which ones are important.

Recently John Donohue and Steven Levitt (2001) have claimed that "legalized abortion may account for as much as one-half of the overall crime reduction" during the 1990s. Two possible hypotheses were advanced. Abortion may have prevented "unwanted" children from being born. These unwanted children might, if born, have had smaller investments in human capital by their parents and thus been more prone to end up in trouble when they grew older. Secondly, there is the less savory issue of whether abortion simply disproportionately culls out certain groups disproportionately involved in crime (e.g., poor black males). Not surprisingly, this entire discussion became very controversial when raised by either Donohue and Levitt, Anthony Bouza (1990), or Henry Morgentaler (1998). ${ }^{3}$

Given the possible racial implications, it is surprising that Donohue and Levitt didn't do more to separate these two possible hypotheses. This concern has been particularly raised by those pointing out that blacks account for over 30 percent of the abortions since the early 1970s. ${ }^{4}$ Donohue and Levitt could have measured whether the drop in crime still occurred after directly accounting for the changing racial composition of the population. ${ }^{5}$

1 Lynette Clemetson, "The Gospel According to John," Newsweek, February 12, 2001, p. 25.

2 For evidence on all these explanations except for abortion see Lott (2000, Chp. 9). See also Donohue and Siegelman (1998) for a related discussion.

3 Henry Morgantaler, one of the leading proponents of abortion in Canada for several decades, notes (1998) that "It is well documented that unwanted children are more likely to be abandoned, neglected and abused. Such children inevitably develop an inner rage that in later years may result in violent behaviour against people and society. ... I predicted a decline in crime and mental illness 30 years ago when I started my campaign to make abortion in Canada legal and safe. It took a long time for this prediction to come true. I expect that things will get better as more and more children are born into families that want and desire them, and receive them with joy and anticipation." Similarly, Anthony Bouza, the Minneapolis police chief, wrote (1990) that abortion is "arguably the only effective crimeprevention device adopted in this nation since the late 1960s."

For examples of the controversy these theories engender see Carl T. Rowan, "Fighting Crime with Abortion?" New York Post, August 13, 1999, p. 29; Editorial, "Eugenics with a happy face," Washington Times, August 18, 1999, p. A16; and Allen Short, "Hatch call Bouza Hypocrite on Crime," Star Tribune (Minneapolis, Minnesota), August 5, 1994, p. B1..

${ }^{4}$ Abortion Surveillance: Preliminary Analysis -- United States, 1996, Centers for Disease Control, December 04, 1998 / 47(47);1025-1028,1035.

5 In a response to this paper when it was presented at the American Law and Economic Association meetings in 2001, Donohue argued that "If abortion is changing a state's demographics, then controlling for demographics is inappropriate when trying to measure the impact of legalized abortion." We would argue that is precisely what you want to account for if you want to see whether the impact of crime is due to the changing quality of people within groups as opposed to eugenics type claim that the drop in crime results from 
While it is indeed quite plausible that abortion would result in fewer "unwanted" children who have smaller investments in human capital and higher probabilities of engaging in crime, this discussion does not exhaust the possible impacts of abortion on crime. Recent work by Akerlof, Yellen, and Katz (1996) in fact suggests the opposite conclusion. They note that the legalization of abortion and the increased availability of contraception to unmarried women increased the number of out-of-wedlock first births. ${ }^{6}$ Everything else equal this theory predicts a reduction in human capital investments in children after the legalization of abortion and, while they don't extend these implications to crime, obviously the prediction for crime is the exact opposite of the Bouza-Morgentaler-Donohue-Levitt hypothesis. Others note that the legalizing of abortion might contribute to a coarsening of society that might itself lead to more crime (Will 2001).

As of now, the Donohue and Levitt study is the only one that has directly linked legalizing abortion to the crime rate. According to the Uniform Crime Reports, the peak in U.S. crime rates occurred in 1991, eighteen years after Roe v. Wade was decided in 1973. Whether that should be the exact point where any impact of Roe should be felt is not clear, though it is surely suggestive. Their evidence depends on crime falling first in the five states that legalized abortion prior to Roe v. Wade as well as whether the crime rates have fallen the most in the states with the highest abortion rates. However, rather than regressing total crime on a measure of total abortions, this paper directly links the number of abortions when a cohort was born to the crimes that cohort later commits. We find that legalizing abortion was associated with a statistically significant increase in murder rates.

\section{The Relationship between Legalizing Abortion and Crime}

The central question is really how abortions alter human capital investments in marginal children. To Donohue and Levitt, the marginal children are ones who would have been born into substantially less favorable circumstances. They cite evidence that aborted pregnancies would have resulted in children who "would have been 60 percent more likely to live in a single-parent household, 50 percent more likely to live in poverty, 45 percent more likely to be in a household collecting welfare, and 40 percent more likely to die during the first year of life" (Gruber, et al. 1999, p. 265). They then point to evidence that unwanted children and those raised in "an adverse family environment" are "strongly linked to future criminality" (p. 11). ${ }^{7}$

In a very different approach, Akerlof, Yellen, and Katz focus on the fate of the children who were born (not on what fate would have awaited each child had they not been aborted). From the 1960s through to the late 1980s (the last years in which births could have any effect on crime rates during the 1990s), there has been a tremendous increase in the rate of out-ofwedlock births. On average during 1965-69, only 4.8 percent of whites were born out-ofwedlock, rising to 16.1 percent twenty years later (1985 to 1989). For blacks, the numbers rose from 34.9 to 61.8 percent. As Akerlof et. al. point out, unmarried women used to be much more likely to put up their children for adoption. In 1969 only about 28 percent of children born out-of-wedlock were being raised by mothers who were still unmarried within three years. By 1984, that same fraction had doubled to 56 percent. Hence, most of the children born out-of-wedlock before legalized abortion ended up in families with a father.

culling out those portions of the population who are likely to engage in crime. However this paper goes further and examines the results both with and without demographics.

6 Grossman and Joyce (1990, pp. 1000-1) provide interesting results that the number of abortion providers in New York City is negatively related to birth weight.

7 The discussion relating human investments in crime is more complicated than this because assumptions must be made about how the reduction reduces the return to legitimate relative to illegitimate activities (Lott 1987). 
To Akerlof, et. al., the legalization of abortion reduced women's ability to withhold premarital sexual favors from men. Women who are willing to obtain an abortion are more likely to engage in premarital sexual activity without a promise of marriage should pregnancy occur. However, other women who are unwilling to obtain an abortion face competition from women who are willing to obtain an abortion as men "seek satisfaction elsewhere" (pp. 2967). Further, as premarital sex and out-of-wedlock births became more common, the stigma declined and social pressure for couples to marry also declined, hence reducing investment in the child. ${ }^{8}$

The two effects are likely to be going on at the same time. "Unwanted" children may indeed become less common after abortion, with those potential children avoiding the problems of an adverse family environment and a higher likelihood of crime. At the same time, other women who want children and are unwilling to have abortions find that they are having to raise children on their own, which also entails a smaller investment in human capital compared to the situation that existed before abortion was legalized. ${ }^{9}$ It is unclear which effect will dominate, and thus whether the investment in children's human capital will increase or decline.

Both effects are also consistent with an observed reduction in fertility rates. Women who do not want children obviously can terminate pregnancies. Women who do not want to avail themselves of abortions are now more willing to engage in risky pre-marital sex would end up with more out-of-wedlock births, but this is still a less attractive option than they faced before abortion was legal when they would have been able to wait until marriage for sex and have had children within a marriage. Women with children may also find marriage at a later date more difficult.

Finally, both theories relate abortion to crime rates through the level of investment in a child's human capital. The percentage of children born out-of-wedlock and the rate at which those children are raised by their unwed birth mother are easily observable, yet it is more problematic to link such time-series evidence to the legalization of abortion. In contrast, the types of homes in which children had they not been aborted would have grown up in is even more hypothetical. By 1980, 665,747 children were born out-of-wedlock and almost 1.3 million being aborted, both numbers are large, but more information is needed to answer what happens to investment in human capital and thus crime.

\section{Changes in Murder Rates by Age Range}

Five states are classified by Donohue and Levitt as legalizing abortion prior to the Roe v. Wade decision in January 1973. California's Supreme Court legalized abortion in late 1969 and Alaska, Hawaii, New York, and Washington legalized abortions through legislation the following year. The data used in their regressions assume that no abortions occur in any state other than these five prior to $1973 .{ }^{10}$ However, there are doubts whether this simple classification accurately reflects the ease of obtaining abortions: abortion data from the Centers for Disease Control indicate that other states which allowed abortions only when the life or health of the mother was in danger actually had higher abortion rates than some states

8 Contraceptives make abortion less of an issue, and it seems likely that the knowledge and correct use of contraceptives is much higher among intelligent women. For them the cost of premarital sex is less and they will face relatively few unwanted pregnancies.

9 However, Bronars and Grogger (1994) find no evidence of the detrimental impact of outof-wedlock births on the mother being transmitted to her children.

10 The correlation between the CDC's measure of abortions and those used by Donohue and Levitt is .91 for abortions from 1973 to 1985 , but it falls to .84 from 1970 to 1985 because of the assumption that there are no abortions in the nonlegalizing states prior to 1973. 
where it was legal (see Table 1). ${ }^{11}$ For example, in 1972, Maryland, Oregon, New Mexico, Kansas, and the District of Columbia had abortion rates that were as high or higher than the states where abortion was legal. Still other states such as Wisconsin, Colorado, and Delaware were not very far behind. Overall 23 states in 1972, 20 in 1971, and 5 in 1970 are incorrectly listed in their data as not having abortions. ${ }^{12}$

Donohue and Levitt have argued since the publication of their paper that excluding abortions in the "nonlegal" states is justified because only relatively well-to-do mothers were able to "game the system" and obtain abortions and that the offspring of these mothers were not the type who would likely have engaged in criminal activity. ${ }^{13}$ Unfortunately there is no direct data on the wealth of the women who have abortions, but we can proxy their wealth by using information on a woman's race. Two different racial categories are available from the CDC: blacks and others or whites. The evidence indicates that if anything relatively poorer women made up a larger share of abortions in the "nonlegal" states. Blacks and other women make 24 percent of the female population between 10 and 49 years of age and the same percentage of live births, but they account for 30 percent of the abortions in "nonlegal" states prior to 1973. By contrast, they make up 32 percent of the female population and 33 percent of live births in the 5 "legal" states, but only 21 percent of the abortions.

While we will rely on Donohue and Levitt's classification in this section, including other states as "early adopters," with abortion rates at least as high as those where it was legal, produces results that were more inconsistent with their hypothesis. ${ }^{14}$ We will graphically examine the changes in crime rates: first comparing murder rates across different age groups in United States over time and second by comparing crime rates in the states that first legalized abortion to other states.

The Supplemental Homicide Reports allow us to disaggregate the number of murders committed by each age for each state. Suppose the legalization of abortion can explain up to half the drop in crime as claimed by Donohue and Levitt. Such a huge drop in crime should be readily observed first in the youngest age categories and then gradually appear in progressively older age groups as they were born after abortion was legalized. To examine this, we broke down the number of murderers into five age categories: 10 to 15 year olds, 16 to 20 year olds, 21 to 25 year olds, 26 to 30 year olds, and over age 30 . By far the highest murder rates (the number of murderers in an age category divided by the number of people of that age) are concentrated in two age categories 16 to 20 and 21 to 25 , with the murder rate for 26 to 30 year olds ranking third.

Figure 1 shows how the murder rates varied by age for the period from 1976 to 1998 . The murder rate changes appear to be more consistent with the theory that legalizing abortion increased, rather than reduced, murder rates. The murder rates for the two oldest age groups ( 26 to 30 and over 30 years of age) fall almost over the entire time period. The next two

11 We used the abortion data from the Centers for Disease Control rather than the data that Donohue and Levitt used from the Alan Guttmacher Institute because that data was not made available to us when we put this paper together.

12 Donohue and Levitt do not include data on the number of abortions prior to 1970.

13 Based upon comments made at the 2001 American Law and Economics Association meetings.

14 Simply to be consistent with Donohue and Levitt we primarily use the number of abortions reported in a state, though it is possible to adjust for whether people are coming from other states to have their abortion. We measure the total number of abortions by state, though the results are extremely similar if we simply used the number of abortions for a state's residents. This is shown in Table 3. 
oldest age groups (16 to 20 and 21 to 25 years of age) both peak in 1993 . Finally, the youngest age group peaks last in $1994 .{ }^{15}$

The next set of figures contrasts the changes in crime over time for five "early" legalizing states with all the other "late" legalizing states. Figures 2A-2E make this comparison for 10 to 15 year olds, 16 to 20 year olds, 21 to 25 year olds, 26 to 30 year olds, as well as for those murderers where the age of the murderer is not known. Murders by those over age 30 are excluded because no one in that category was born after the legalization of abortion. Besides the murder rates for the "early" and late legalizers, the dotted vertical lines indicate the years when legalization begins to apply to people in the age range. ${ }^{16}$ For example, the first people born after the legalization of aboration in the "early" legalizing states were born in 1970 and didn't start to enter the 10 to 15 age category until 1980. Since legalization is not assumed by Donohue and Levitt to have occurred in the "late" adopters until 1973, there should be no affect on crime by 10 to 15 year olds in those states until 1983 .

Figures A, B, and C show several striking similarities. The patterns are remarkably similar over time when one compares the "early" legalization patterns across age groups to each other. The 10 to 15 year olds in the early adopters in Figure A can not be affected by abortions until 1980 and the early adopters in the older age groups in Figures B and C can not affected until 1986 and 1991, respectively. Thus, if abortion is driving the murder rates for the early adopters in the first three figures, the patterns should be lagged by about six years for 16 to 20 year olds and then another five years for 21 to 25 year olds. Instead the three early adopter patterns are remarkably similar to each other. All three rise from 1976 to 1980, then fall from 1980 to 1984, then rise into the 1990s, and finally fall together again over the last five years. The same similarity also holds true for the three late adopting patterns. All three decline from 1980 to 1984, then rise, and then fall together again.

Figures $2 \mathrm{~A}$ to $2 \mathrm{D}$ further show a remarkably similar pattern across early and late adopting states despite abortion legalization affecting the late legalizers with a three year lag. It is also clear that despite legalization beginning to affect people in the different age groups at different times there is little obvious relation to any changes in murder rates. While murder rates declined when abortions were legalized for early adopters for 10 to 15 year olds and early and late adopters for 21 to 25 year olds, murder rates rose after legalization for late adopters in the 10 to 15 year old age range and early and late adopters for 16 to 20 year olds. Examining both early and late adopters for the 26 to 30 year old age group, the legalization of abortion does not seem to speed up what had been a fairly continuous drop in murder rates over the whole period. If legalizing abortion is having any effect on murder rates, it is not obvious from this raw data. ${ }^{17}$

15 While we are focusing on who is committing the crimes, it is also possible to produce a figure for the victimization rate and it produces a similar pattern where the victimization rate for the oldest people begins to decline first.

Another way of summarizing this information is to examine the average age of murderers. If murder rates first declined among the youngest, the average age of murderers should be rising. Yet, as Figure 1 implies, the average age of murderers fell almost continually from the mid-1970s to the 1994, declining from 30.9 years of age in 1977 to 27 in 1994. Only after 1994 has there been a slight rebound in the average age as the younger age groups began to reverse their increase in rates of committing murder which began in the mid-1980s. By 1998 , the average age of murderers had risen back up to 28 years of age.

16 The numbers in Figure 2A prior to 1980 are calculated slightly differently than the other numbers because of the inability to precisely link the ages of population with crimes by this age group. To make this link we assumed that the population group for 5 to 13 year olds was uniformily distributed.

17 The gap between early and late adopters also does not vary in ways that can be explained by the legalization of abortion. For example in Figures $2 \mathrm{~A}$ and $2 \mathrm{~B}$ the gap between early 
Figure 2E, which shows the murder rates for murderers of unknown age, indicates the murder rate peaking in 1993 for the early adopters and 1994 for the late adopters. Again, the timing of these peaks do not seem consistent with legalized abortion: there is no difference in when the peaks in murder rates occurred and there is too long of a lag after legalization.

It is also possible to track some cohorts over time. The top panel in Figure 3 is for people born immediately two years before or two years after the legalization of abortion in the five early adopting states. The second panel does the same thing for those living in the 45 states and the District of Columbia who were affected by Roe v. Wade. The graphs tack these cohorts crime rates from their teens through their twenties. There is some difference in murder rates as these cohorts age, particularly during the late teenage years. For example, in panel B while the murder rate among those born after legalization rises faster up until age 18, this group also has a slightly faster decline in murder rates after that point. In panel A, those born prior to legalization have higher murder rates for 9 ages and the reverse is true for 5 ages. It is possible to include additional years before and after legalization and this does show a somewhat higher murder rates during middle age years for those born after legalization (e.g., see Appendix Figure A1 which shows a period of four years before and after legalization), but allowing more years to elaspse between cohorts makes comparisons more difficult because other factors may be changing. ${ }^{18}$

Finally, a breakdown according to the sex of the murderer is also possible. Some abortions are done to selectively choose the sex of infants, and this has become progressively easier over time. The presumption is usually that female offspring are less desired than males and thus aborted at relatively higher rates. ${ }^{19}$ Even if this is not so, the Bouza-MorgentalerDonohue-Levitt hypothesis about unwanted children would seem to predict at least some drop in murders by women during the 1990s. Yet, murders by women fell almost continually during the 1980s and 1990s (See Figure 4). The entire difference between overall murder rates increasing in the last half of the 1980s and the dropping during the 1990s is driven by males committing murder. Breaking down murders for women and men by the age of the killer (not shown here) again confirms what was first reported in Figure 1: the drop in murder rates are first observed for the oldest age categories.

and late adopters falls from 1980 to 1985 in both graphs even though legalization cannot possibly begin to impact the 16 to 20 year olds in Figure 2B until 1986. After 1990 the differences between early and late adopters narrow in both states, but the legalization of abortion can not explain the narrowing in crime rates between early and late adopters after 1990 since by that time the relevant cohorts in both sets of states were affected by legalization.

18 Graphs showing one and three years before and after the legalization are also available from the authors.

19 The explicit systematic use of abortion to select male offspring appears most widespread in Asian countries and India, but discussions also arise in the American press. See Michael Breen, "Daugthers Unwanted: Asian's preference for sons makes abortion rate soar," Washington Times, Saturday, February 13, 1993, p. A1; Sharon Rutenberg, " 'Custommade' families by sex selection," United Press International May 31, 1983, Tuesday; Owen D. Jones, "Made-to-Orders Babies," Connecticut Law Tribune, September 6, 1993, p. 19; and Reuters News Service, "China Outlaws Sex-screening; Beijing Follows India's Lead to Prevent Mass Abortion of Girl Fetuses," St. Louis Post-Dispatch, November 20, 1994, p. $11 \mathrm{C}$. 


\section{How to Test the Relationship between Abortion and Crime}

Past research has examined how the legalization of abortion altered crime rates, but it did not disaggregate the crimes by the age of the criminal. ${ }^{20}$ To try to deal with this, Donohue and Levitt create an "effective abortion rate" which weights the number of abortions in different past years by the percent of total arrests for a particular crime that occur for people who were born in that year. It is a creative approach, but, as with most aggregation problems, there are serious risks. One of the dangers in using the aggregate crime rate across all ages is that they may incorrectly link changes in total crime rates to the wrong age groups. At the end of their paper they do breakdown the data age of arrest, but that data does not link the arrest to the year in which the crime was committed (Lott 2000) and a high proportion of violent and property crimes are never solved through arrest. ${ }^{21}$

Donohue and Levitt also made other compromises in creating the "effective abortion rate." They assume that the relative rates at which different age groups commit crime is not only the same across all states but is also constant over time. A breakdown by the age of the criminal is only readily publicly available by state by year for murderers through the Supplemental Homicide Reports. These data show that this assumption is very unrealistic. The share of murders by different age groups varies tremendously over time. For example, while murders by 16 to 20 year olds made up 12 percent of total identified murders in 1984, they made up 21 percent in 1994.22

Similarly, the assumption that crime is committed at the same rate by different age groups across states and over time is another oversimplification. Figure 5 shows how the standard deviation of age group shares varies across states over time. The standard deviation across states in the share of murders attributable to 16 to 20 year olds and 26 to 30 year olds fell by over 50 percent in a single year (1982 and 83 and 1990 and 91, respectively). On two occasions (1986 to 87 and 1991 to 92 ) the standard deviation across states in their share of murders committed by those between 10 and 15 doubled. Similar large jumps occurred for the share of murderers over age 30 .

While it is unclear what types of biases this aggregation creates, what is clear is that the aggregation eliminates a great deal of information, not only on how the age distribution of criminals is changing over time but also how it is varying across states. Comparing the total number of murders with their aggregate measure of "effective abortions" and assuming a 15 to 20 year lag before abortion materially affects crime makes it difficult to know what we can infer from the type of panel data set that Donohue and Levitt have constructed.

However, we can examine whether their weighting scheme or assumption that abortion rates were zero in the "nonlegalizing" states has any systematic effects. To do this, we replicated the results reported in Donohue and Levitt's Table IV using the data that they supplied us and then examined three types of variations: 1) assuming that no abortions occurred when not defined as "Legal" by Donohue and Levitt or using CDC abortion data for all years in calculating the "effective abortion rate," 2) using national average weights for 1985 or state and year specific weights in calculating the "effective abortion rate," and 3) using either the

20 More recently work by Joyce (2001) also breaks down the data by cohorts, though he uses selective cohorts with a difference-in-difference-in-difference method. Like our work here, he did try using count data models to estimate these results but was unable to do so because the specifications did not converge (p. 14, fn. 14). He does report though a large number of estimates and generally concludes that there is no relationship between the legalization of abortion and the level of violent crime, property crime and homicide.

21 Donohue and Levitt (fn. 34) themselves acknowledge the problem with arrest rate data of linking the criminal's age to the year of the crime.

${ }^{22}$ Even though Figure 1 shows the variation in rates and not shares, a figure showing different age groups' share of total murderers also varies similarly over time. 
UCR murder rate or the murder offender rate from the Supplemental Homicide Report. Despite repeated requests, we were unable to ascertain exactly what age ranges were used in calculating the weights used by Donohue and Levitt in constructing the "effective abortion rate." Fortunately, the Supplemental Homicide Report supplies information on offender rates by individual year of age. We can thus weight the index by abortions in the year of birth for all the criminals for all ages that are affected by abortion.

The results for these different permutations are shown in Table 2. Using the data supplied by Donohue and Levitt, we had no problem replicating the statistically significant and large abortion coefficients in their columns 5 and 6 and these are reported in our rows 1 and 5 for column 1. The control variables and the sample period are exactly the same as they used, and the coefficients on these other variables are also the same as those they report. Continuing to focus on the UCR murder rate, replicating their effective abortion rate using the Supplemental Homicide Report in rows 2 and 6 drastically reduced the impact of abortion on murder by between 50 and 69 percent and was no longer statistically significant. When we dropped the assumption that abortions only took place in the five states that Donohue and Levitt identify as "legal" abortion states the size of the coefficients in rows 3 and 7 were further reduced by another 20 to 40 percent. Finally, using state and year specific weights instead of a national average (which is constant across all states for all years) reverses the sign of the coefficients and implies that more abortions increase murder rates, though neither coefficient was found to be statistically significant at the 10 percent level. ${ }^{23}$ A similar pattern also arises when the UCR murder rate is replaced by the offender rate in column 2 .

Donohue and Levitt's results in their Table IV column 6 implied a 0.43 percent drop in murder for each one percent increase in abortions. This accounts for 25 percent of the 30 percent drop in murder between 1991 and 1997. By contrast, when we used all the abortion data available and used state and year weights in determining the share of crimes committed by each age group rather than assuming constant shares across states and years, the same specification implies that each one percent increase in abortion raises the murder rate by 0.08 percent. Everything else equal, abortion would have slightly increased murder rates by 1.3 percent between 1991 and 1997.

As we noted earlier, the major benefit of the Supplemental Homicide Report is to move beyond these aggregate crime and abortion numbers and directly link the age of the murderer with the year in which the crime occurs. To use this data in a regression analysis, we set up panel data to examine the number of murders committed by each year of age by state by year. We break down the individual ages by year from 10 to 30 years of age and then aggregate together all the murders committed by those over age 30 . The age groupings are disaggregated by year born for those born when abortion may have been allowed. This panel allows us to track each cohort as they age and account for the number of legal abortions in their state in their year of birth. If abortion eliminates those in the population who are most likely to commit murder, we should observe a significantly lower murder rate among those who were born immediately after legalization. Further, that difference should be traceable over time as each cohort ages.

In their estimates explaining arrests for violent crime (Table VII), Donohue and Levitt drop observations where there are zero arrests for a given age. Yet, excluding observations based upon on the realization of the dependent variable creates a potentially important selection bias. This problem is particularly acute for murder, which is less frequently committed than

23 One possible reason for using the national weighting that is constant across years and states that has been mentioned to us by Steve Levitt is that allowing the weights to vary would induce an artificial correlation between the murder and effective abortion rates. Presumably, the relationship is similar to that which exists between the murder and arrest rate in crime regressions. Yet, that does not appear to be relevant here because what is really being compared is the share of murders by people under age 29 and the murder rate. 
either overall violent or property crime, and it is the reason they cite for not reporting these estimates for murder. Following Plassman and Tideman (2001), we deal with the count nature of the data by estimating Poisson regressions. For those who are interested, a distribution of the murder data from the Supplemental Homicide Report is presented in Appendix Figure A2.

Obviously many factors affect the rate at which people commit murder. The most basic regressions include age, state, and year fixed effects. We also include the population in the state that are the same age as the murderers. Law enforcement efforts against murder are measured by arrest rates for murder, the execution rate in the year that the crime occurred, and the percent of the population in prison. ${ }^{24}$ Both the last two variables are problematic since crime and enforcement rates in the past as opposed to current efforts are much more important in determining their current values. This is probably less of a difficulty for execution rates since changes in who is governor or changes in the composition of the state supreme court can have a big impact on the number of executions that take place. Using the general prison population as a percent of the total population also has the problem that only about one or two percent of prisoners are incarcerated for murder and any changes in enforcement against murder are likely to have small changes in even this tiny fraction because prison sentences for murder are so long. ${ }^{25}$ The bottom line is that the variable we would like to measure -- prison sentences as deterrence against murder -- would likely be swamped by the changes in enforcement for other crimes. However, the results reported here are not much affected by the inclusion of any of these variables and we include the percent of the population in prison simply to make our results consistent with Donohue and Levitt's.

Other factors that we account for are the unemployment rate; the poverty rate; real per capita personal income; real per capita government payments for income maintenance; unemployment insurance and retirement payments; state population density in miles; a set of demographic variables that subdivide a state's population into 36 different race, sex, and age groups (see Appendix 1); and the trends before and after the passage of right-to-carry laws. With the exceptions of broader measures of income and the inclusion of demographics, the variables are very similar to those used by Donohue and Levitt. We have included these other variables because they have been used in our past work (e.g., Lott 2000) and because of the discussion in the introduction about the importance of demographics in determining that any changes in crime are not simply due to groups which commit crime at high rates being culled out of the population. Still, as we will show below, for this panel the results we report are not dependent upon any particular set of control variables. ${ }^{26}$

24 For discussions of these variables see Lott (2000) and Marvell and Moody (1994). 25 There are other theoretical problems with using the prison population. For example, prison population is a stock while the crime rate is a flow. The difficulty that this creates is that the prison population is determined by enforcement over many years, but it is the current level of enforcement that is important for determining the crime rate.

26 While it is difficult to directly measure the violence caused by cocaine/crack, limited cocaine price data is available for a portion of the sample from 1980 to 1992 (with the exceptions of 1988 and 1989) to proxy for the relative accessibility of cocaine in different markets. Using yearly state-level pricing data (as opposed to more short-run changes in prices) also has the advantage of picking up cost and not demand differences between counties, thus measuring the differences in availability across counties. The data was obtained from Grossman et. al. (1996). The county level data is aggregated to the state level by weighting the prices by the population in the counties. The reduced number of observations provides an important reason why we do not include this variable in the regressions shown in the text. Including it leaves the coefficient on abortions virtually unchanged. While simply using the price does not allow one to perfectly disentangle local differences in demand and supply, arbitrage basically assures that except for short periods of time the differences in prices between these local markets will equal differences in selling costs. If the total cost of selling cocaine was the same in two different cities, any price 


\section{Measuring the Impact of Abortion on Crime}

The panel data set covers murders committed by murderers in 22 age categories (by year of age from 10 to 30 and over 30), 50 states and the District of Columbia, and years from 1976 to 1998 . In addition, 23 percent of the murders are in a 23rd category covering murders committed by criminals of unknown age. Potentially there are 26,979 observations, though that is reduced to 21,480 because of missing observations, particularly the population by year of age which is only available starting in 1980 .

The first issue is what to do with the unknown age category. There are several possible approaches: 1) exclude murders where the age of the criminal is unknown, 2) include all murders but use additional dummy and trend variables to proxy for the impact of abortion for those observations since abortions numbers are not available for murderers of unknown age, or 3) use estimates included in the Supplemental Homicide Reports that distribute the unknown murderers based on the known distribution by age/race/sex of offenders by state and year. The first two approaches create problems by either censoring the endogenous variable or not being able to link the unknown murderer category to the abortion variable. The third approach is problematic because unknown murderers may be different from murderers who have been identified if only because they are more difficult cases. ${ }^{27}$ The chief advantage of the second approach is that it does not discard any information. While we shall primarily report the results using the second approach, we tried all three, though the results for the abortion variable differed very little across specifications.

For the second approach, we estimated the following regression:

Murders $i_{i j k}=\beta_{1}$ Abortions $_{\mathrm{ijk}}+\beta_{2}$ Population of Age Cohort Ajk $+\beta_{\mathbf{3}}$ Control Variables $\mathrm{jk}_{\mathrm{j}}$ $+\beta_{4}$ (State Fixed Effects* Time Trend that is non-zero when the age of murderer is unknown)

$+\beta_{5}$ State Fixed Effects $+\beta_{6}$ Age Fixed Effects $+\beta_{7}$ Year Fixed Effects $+\alpha+\varepsilon_{i j k}$

"Murders" are the number of murders committed by a murderer of age $i$ in state $j$ and year k. "Abortions" are the abortions that took place in that state when that cohort was born, and "population" is the number of residents of age $i$ in state $j$ and year k. For murders where the age of the murderer is unknown, the abortion variable equals zero but the vector of state specific time trends for just that category is non-zero (so as to account for the otherwise unmeasured impact of abortion for unknown age murderers). We also have vectors of control variables and state, age, and year fixed effects.

Table 3 examines the simplest specifications that include all the variables and observations and examines whether the results are affected by how the law enforcement variables are accounted for. The columns show different specifications with various sets of control variables, though all include state, year, and age fixed effects. The first column shows the

differentials resulting from sudden shifts in demand would result in distributors sending cocaine to the city with the higher price until the price had fallen enough so that the prices between the two cities were equal. Distributors could even remove cocaine from the low price city and move it to were it could obtain a higher price. Sellers in a city could also hold inventories and not sell their cocaine during periods with unusually low demand. To the extent that it is costly to instantly move drugs between different cities or to store drugs, any price differentials in the short run can be due to demand shifts, but since we are dealing with a period of a year, it seems difficult to believe that any noncost based price differentials will not be arbitraged away.

27 Joyce (2001) uses imputation method provided by the Supplemental Homicide Report and he is aware of the problems that this creates, though he appears to be unaware that the data is available without this lumping of known and unknown data together.. 
relationship between the number of murders and abortions, and the second specification includes all the other control variables. One concern with this simple specification is that the total arrest rate for all ages for murder affects the number of murders and the reverse is also true. A similar simultaneity exists for the overall prison population, but it is much less of a problem since murderers make up only a percent or so of the total prison population. The next two columns show methods to deal with these simultaneity problems. The third specification uses lagged values for the arrest rate and prison population, ${ }^{28}$ while the fourth specification replaces the arrest rate for murder with the arrest rate for overall violent crimes. The arrest rate for violent crimes will still proxy for the effectiveness of police but avoid being very closely effected by contemporaneous changes in the number of murders.

The final two specifications use a dummy variable for the legalization of abortion as well as the natural log of all the abortion and population variables. ${ }^{29}$ An advantage of using the simple dummy variable as opposed to the number of abortions is that it is more clearly exogenous, especially because other socially factors might be changing over time that influence both the abortion rate and how children are raised. On the other hand, while the dummy variable will give us a measure of the average impact of the law, the number of abortions allows us to measure the differential impact of legalization across different states. The log specification not only allows the interaction of the abortion and population variables, but it allows us to use nonlinear values for those variables and puts a smaller weight on the impact of abortion in the larger states.

The top row of Table 3 reports the percent change in murders by people of a certain age from a thousand abortions for people of that age. These incident rate ratios are reported throughout the paper indicate that murders are increasing when the coefficient is greater than one and declining when the values are less than one. Interestingly, all the estimates imply that more abortions produce significantly more murderers when children get older. Even though the coefficients for the first four specifications are remarkably consistent, the effect is extremely small. The average state had 25,443 abortions in 1980. One thousand more abortions at the time that people were born (i.e., about four percent of the average) is associated with about a .018 percent increase in murders in any given year. Going from zero abortions to the average number of legal abortions will increase the murder rate by less than a half of one percent. ${ }^{30}$

The last two columns imply somewhat different impacts from abortion. The simply dummy variable reported in column 5 indicates that legalizing abortion produced on average a 7.3 percent increase in murder. Whether this increase is due to the legalization of abortion for the two sets of states in 1970 and 1973 and not other general cultural factors that are also changing at about this same time is hard to say simply because there is so little difference in the adoption dates. When evaluated at the mean, the sixth column which examines the log of the number of abortions implies that a thousand more abortions will increase the number of murders by 0.13 percent. However, this nonlinear result implies that the legalization of abortion increased the murder rate by 11 percent. While not reported, we also ran the simple

28 Lagged values are problematic because in theory it is the current arrest and punishment levels that should matter most in deterring criminals. The benefit from lagging the prison population also seems extremely small because murderers make up such a small portion of prisoners.

29 For observations where the abortion variable equals zero we added .1 before taking the natural $\log$.

30 There is also the issue of whether the results are consistent across states or are being driven by a few unusual outliers. To test this, we interacted the abortion variable with a set of state dummy variables. With Alabama serving as the left out state, 42 states have higher crime rates as abortion increases, 39 of them statistically significant at least at the 10 percent level for a two-tailed t-test. For six states the effect was negative, but more abortions significantly reduced murder rates in only two states (Nebraska and Vermont). 
dummy variable and natural log specifications that correspond to specifications 1,3 , and 4 and the abortion results changed little from those reported in columns 5 and 6.

The linear estimates imply about 78 more murders a year in 1998 as a result of abortion being legalized. The simple dummy variable implies that something significant changed in 1970 and 1973 for the two sets of states affected in those years. This higher estimated increase in murder implies that legalizing abortion raised the number of murders in 1998 by 1,230. Finally, the natural logarithm estimates indicate that legalization raised produced over 1,850 more murders in 1998.

The specifications corresponding to those in Table 3 when we use the Supplemental Homicide Reports' method of distributing unknown murderers or exclude murders where the age of the criminal is unknown are reported in Appendix 3. In all these specifications the impact of abortion is statistically significant at well above the .01 level for a two-tailed t-test, and the effect is between 4 and 28 percent larger than those reported in Table $3 .{ }^{31}$

The law enforcement variables all have the expected effects, with more arrests and executions and more people in prison all associated with reductions in murder, though the effect is not always significant for the execution rate. A one percentage change in execution rates however has a much bigger impact than either a one percent change in either of the two other law enforcement methods. Consistent with past research, murder rates fall at least 1 percent per year faster after the adoption of right-to-carry laws and the F-statistics equal at least $17 .{ }^{32}$ States that are more densely populated have higher murder rates. Poverty rates produce no consistent effect on murder, the effect is never statistically significant. The most surprising result is the usually significant reduction in murder rates from higher unemployment rates, though the effect is small -- each one percentage point increase in unemployment reduces murder rates by about one percent. The estimates for the impacts of the demographic variables and age dummies that correspond to column 2 are shown in Appendix 2.

The results in Table 4 correspond with the sensitivity test provided in Donohue and Levitt's Table V, with two exceptions: an additional row limiting the sample to just those of known ages affected by the legalization of abortion and replacing all the nonage specific state-year level variables with state specific year fixed effects. The full set of control variables and sample is reported in the first row as the baseline. Each row represents a separate specification. Donohue and Levitt tested whether the results were sensitive to "large states," states with "very high or low abortion rates" as well as different types of trends and fixed effects. The large states excluded are California and New York and the jurisdiction with the high abortion rate that is excluded is Washington, D.C.. Each is excluded separately and then all three are excluded as a group. Individual state specific trends and separate regional fixed effects by year are also tried. Because of our statistical package's (STATA) limit on the number of control variables using state specific year fixed effects may more effectively control for year to year variations in factors that affect the overall level of crime but it comes at a cost of having to restrict the number of years that can be examined. The last row in each of the three sections in Table 4 reports regressions that account for the number of abortions,

31 However, as we were concerned that would happen, excluding those cases for which the age of the offender was never known did alter other coefficients such as the arrest and execution rates.

32 A data set with information on other gun control laws for a portion of the time period studied here from 1980 to 1997 was also used to estimate these regressions, but their inclusion had little impact on the size or significance of the abortion variable. The data are discussed in Lott and Landes (1999) and include information on waiting periods, background checks, penalties for using guns in the commission of crime, and so-called safe storage laws which imposes penalties on adults who do not lock up there guns if the guns are used improperly by a juvenile. 
the age specific population, a state specific trend variable for unknown age murders, as well as state specific year effects for the period from 1989 to 1998.

All of our twelve linear specifications still indicate a significant increase in murder rates from more abortions and the effects are all statistically significant at least at the .01 percent level. Most of the results produced coefficient estimates very similar in size to those discussed in Table 4, though two of the cases where observations were excluded implied dramatically large increases in murder from abortion. The twenty-four dummy variable and natural log estimates imply an even more consistent relationship and always show a significant positive relationship between abortions and crime.

There are other sensitivity tests that can be made. We categorized the control variables used in Table 3 into 10 different sets: the execution rate, prison population, arrest rate, the four measures of income, population density, unemployment rate, poverty rate, right-to-carry laws, population of the age group committing murder, and the 36 demographic variables. Running all combinations of these control variables results in 1,024 regressions. We then broke this down further into two different sets: the state, age, and year fixed effects and those fixed effects with an additional time trend for each state. Doing this for all the linear, dummy variable, and the natural log specifications doubles the number of regressions. Taken together, we ran 6,144 regressions.

The results from this specification search are summarized in Table 5 and they show an extremely consistent significant increase in murder rates from the legalization of abortion. For all 2,048 linear regressions, increasing the number of abortions by a thousand increases the murder rate by between .0013 and .003 percent, and all but one of the coefficients were statistically significant at least at the 10 percent level for a one-tailed t-test. ${ }^{33}$

We finally examined whether abortion had a different effect on crime as people aged. It is not obvious that the percentage increase in crime should be the same for all ages. To do this, we tried two different approaches. First, two new variables were added: the abortion variable interacted with murderer's age and also with age squared. Both new coefficients had zstatistics of at least 13.8 and indicated that the greatest percentage increase in murder rates at 20.3 years of age. ${ }^{34}$

Second, the three measures that we have been using were interacted with the age dummy variables. The results reported in Table 6 imply a much more complicated story than we have seen thus far. While abortions are on net associated with increased murderers, the impact is not the same for all ages. The three different specifications imply lower but not always statistically significant effects for 10 to 11 year olds, no consistent results for 12 to 15 year olds, and a generally positive and significant impact for those over 15, though inconsistent results again arise for 20 to 22 year olds. Why the only consistent significant results are for children in their late teens and mid to late 20s is not clear, but older teenagers are clearly adversely susceptible to the impact of abortion on crime. Whatever benefits occur for 10 and 11 year olds, the small number of murders committed by this age group is overwhelmed by the higher murder rates committed by the older age groups that are adversely affected by abortion.

\section{Disaggregating Crime and Abortion Rates by Race and Sex}

33 In an earlier version of the paper, we ran these 6,144 specifications without the category of unknown murderers. The ranges of estimates were similar to those reported here.

34 The coefficient for age*number of state abortions in thousands is 1.00042 (z-statistic 22.778 ) and for age $2 *$ number of state abortions in thousands is .9999792 (z-statistic -22.496). 
Legalized abortion need not affect all population groups equally. White, blacks, and other groups obtain abortions and have out-of-wedlock births at different rates. The net effect of legalization is unclear since the groups that have a high levels of abortions also tend to have out-of-wedlock births more frequently. For example, while blacks account for 29 percent of abortions during our sample, they account for about 40 percent of the out-of-wedlock births from 1980 to 1995. Fortunately, the Supplemental Homicide Report disaggregates murders by race, sex, as well as age. The Centers for Disease Control abortion data does list the number of abortions in each state by whether the mother is white or nonwhite, though this information is missing for 1969 and 1982 to 1986 . With the exception of replacing the earlier endogenous variable for the total number of murders with the number of murder broken down by race and sex, replacing the total number of abortions with the number of abortions by the birth mother's race, and examining only those murders for which the race and sex of the murder is available, the regressions correspond to those reported earlier in Table 3. Unfortunately, because the abortion data does not disaggregate nonwhite abortions further by race.

A total of 12 regressions are reported in top half of Table 7.11 of the 12 specifications imply that increases in the abortions of a particular race produce statistically significant increases in murder rates by people of that race, and all 11 are statistically significant at least at the 5 percent level for a two-tailed t-test. The regressions imply that more abortions by white or nonwhite mothers are associated with more murders by people in their respective groups. White males consistently and statistically significantly are more adversely affected by higher abortion rates than white females, and the difference are always statistically significant at least at the 5 percent level for a two-tailed test. For nonwhites the difference between males and females is more mixed: in one cases males face the significantly greater loss, in two case females.

The different specifications do not imply that anyone group is harmed consistently more than another. The linear and natural log estimates imply that on average additional abortions harm nonwhites the most, while the dummy variable indicates that this is true for whites.

The bottom line is that increasing the abortion rate consistently results in more murderers when the remaining offspring of that race come of age, and the effect is larger for white males than white females. Generally the coefficients are similar in size to what was reported earlier, though some are as large as two or three times as large as the average effects reported earlier. Why white males exhibit a larger percentage increase than white females in becoming murderers from additional abortions is not clear but the effect is consistent and large.

There is also the question of who are the victims of this increased crime. Overwhelmingly, most murder victims are killed by people of the same race, but those ratios could change as more murders occur. The second half of Table 7 disaggregates murders by the race of the victim and criminal. For example, in the first specification, the endogenous variable is the number of murders by whites of nonwhites. Since this regression only examines murders by whites, only the number of abortions by white mothers is controlled. Similarly, murders by whites of whites is also examined and so on for murders committed by nonwhites against whites as well as nonwhites. Abortions seem to produce similar increases in murders by whites of both groups. The data is more mixed with for nonwhites and others with the linear and natural log specifications implying much bigger percentage increases in murders of nonwhites and others than for whites, but the reverse being true for the dummy variable specification.

\section{Measuring the Impact of Abortion on Arrest Rates}


Donohue and Levitt directly link abortions to the arrests by year for 15 to 24 year olds using data from 1985 to $1996 .{ }^{35}$ As noted earlier, there are problems with using arrest rates as opposed to the Supplemental Homicide Report because arrest data does not directly link the criminal to the crime and arrests frequently do not occur in the year the crime was committed. The Supplemental Homicide Report also includes information that the local law enforcement agency has on who they thought committed the crime even if an arrest does not take place. The correlation between arrests for murder and the Supplemental Homicide Report for 15 to 24 year olds is still a substantial .93. Any problems will be much greater for overall violent and property crime because of the much lower rate at which arrests are made and the longer lags that tend to exist between the crime and an arrest.

While there are some control variables that differ from our research (e.g., the lack of any demographic variables in their regressions), the last two regressions reported at the end of the sections for violent and property crime and murder correspond to the odd numbered regressions in their Table 8.36 The big difference between their results and ours stems from them assuming that no abortions took place in the late adopting states from 1970 to 1973 and particularly that no observations were included for births that took place prior to 1970 . Expanding the data set so that it covers arrests over the period from 1980 to 1996 also produces stronger evidence that abortion increases arrests for violent crime and murder. The other estimates are based upon the Poisson regressions that we reported earlier. However, with few of the age groups examined experiencing zero violent crime arrests in any given state during a year and none of the age groups experiencing this for property crime, the benefit from using Poisson regressions is limited primarily to arrests for murder.

The results reported in our Table 8 lend little support for the original arrest data reported by Donohue and Levitt. For the weighted OLS regressions that most closely correspond with their original estimates only one regression for property crime implies that higher abortion rates reduce that type of crime. Overall only the arrest for murder regressions always imply the same relationship between abortion and crime, and indeed the effect is frequently two times larger than what we found using the Supplemental Homicide Report, though this is really a result of the narrower age group being examined. It is unfortunate that Donohue and Levitt do not provide results for this crime category so that we can make a comparison. While there are estimates for both violent and property crime that imply both increases and decreases from abortion, one conclusion is clear: the effects are always small and imply that going from zero abortions to the mean number in 1980 had only around a percentage point or so effect on crime.

While there are difficulties with using arrests and not data such as that provided by the Supplemental Homicide Report, neither the different data source nor the limited sample is alone sufficient to explain the different results. Part of the difference between our results and theirs goes away when we assume that abortions only occurred in the five states they define as early legalizers, still that does not qualitatively change our results.

Combining our earlier results from Table 3 with these general estimates for violent and property crime allow some rough estimates of the victimization costs of crime. Donohue and Levitt suggest that abortion reduces annual victimization costs by $\$ 30$ billion, with most of this coming from reductions in murder (Miller et. al. 1993). Using their same calculations for our results from specification 2 imply that abortion raises victimization costs from these higher murder rates alone by $\$ 276$ million per year in 2000 dollars. Even if we take our

35 We limited our sample to that reported by Donohue and Levitt for consistency, but using a sample that for the ages and years reported earler produces results which are generally less consistent with their estimates.

36 We have been unable to determine what they meant by "state*age interactions, but have assumed that they are referring to fixed age effects by year, though interacting state fixed effects with the age variable does not appreciable alter the results. 
estimates on the most optimistic reductions in property crime, the net effect of abortion is to increase victimization costs by over $\$ 200$ million per year. The higher estimated increases in murder imply that legalizing abortion raised the number of murders in 1998 by 1,230 and raised total annual victimization costs from all crime by at least $\$ 4.5$ billion.

\section{Does Abortion Lead to More Out-of-Wedlock Births?}

The research by Akerlof et. al. raises the issue of abortions and contraceptives leading to more out-of-wedlock births. Yet, their empirical work is preliminary and is based on purely time-series evidence. 37 ARMA regressions are used to examine whether there was a change in abortions, use of the pill during first intercourse, and the percent of women before and after 1970 or 1971 who had sex by 16 years of age. They also examine whether there was a change in so-called "first-birth shotgun marriages," where couples were pressured to marry, before and after 1968. All the variables change in the expected way. Abortions, use of the pill, and early intercourse are all higher after the early 1970s, and shotgun marriages are lower, but only for whites.

Compared to panel data, it is rather difficult to disentangle different factors using time-series data alone. Fortunately, state level data are available by year on the rate of out-of-wedlock births and as we have discussed there is a clear difference over time and across states in abortion rates. On the other hand, state level measures of the availability and use of contraceptives are less obvious, though we hope that year fixed effects combined with data on demographics and income will proxy for these differences.

With a few exceptions, we estimated Poisson regressions that account for the same factors that we used in the earlier regressions. The three differences are: excluding the deterrence variables, including a variable for the number of births, and excluding the age fixed effects. Deterrence variables and age fixed effects are no longer relevant to explaining out-ofwedlock births.

The results in Table 9 provide some inconsistent support for the Akerlof et. al. hypothesis, though the effect represents just a tiny fraction of a percentage point. In column 1, each one thousand more abortions is associated with a .007 percent increase in out-of-wedlock births. With about 1.6 million abortions taking place a year from around 1980 on that implies about 11,200 more out-of-wedlock births annually. The linear estimates for abortion implied that legalization resulted in around 77 more murders annually in 1998, about 0.7 percent of a year's worth of out-of-wedlock births. Obviously the effective rate of murderers is much lower as these people may commit multiple murders over many different years. If the higher estimates of up to a thousand more murders per year arising from abortion are true, this figure represents around 11 percent of the annual number of out-of-wedlock births and this number only appears plausible if a small number of these people are responsible for a large number of murders over multiple years. The other estimates in the second and third columns indicate similarly small though inconsistent effects. They imply that it is not the legalization of abortion per se that is associated with more out-of-wedlock births but that those states which had the biggest increase in abortion which are some how different than other states. While higher unemployment, poverty, and income are associated with more out-of-wedlock births, one surprising result is that when controlling for other factors more densely populated states have slightly fewer out-of-wedlock births.

Other possible explanations for why abortions increase crime (e.g., the legalization of abortion leading to a coarsening of society) are beyond the scope of this paper, though the results in this section raise questions about exactly how abortion increases crime.

37 The careful work of others such as Gruber et. al. (1999) have questioned the Akerlof et. al. findings and their research leaves us uncertain in the end as to the final explanation as to why murder rates rise with the legalization of abortion. 


\section{Conclusion}

There are many factors that reduce murder rates, but the legalization of abortion is not one of them. Of the over six thousand regressions that we estimated here, only one regression implied even a small reduction in murder rate. All the other estimates implied significant if very small to modest increases in murder rates: legalizing abortion would increase murder rates by around 0.5 to 7 percent. Yet, presumably the lower end estimates would not appear to have a significant impact on the overall abortion debate. Donohue and Levitt suggest that abortion reduces annual victimization costs by $\$ 30$ billion, with most of this coming from reductions in murder. Our results indicate that total victimization costs rose as a result of abortion.

Many times academics can not avoid using aggregate crime data. Yet, the linking of abortion and crime is not such a situation: examining total crime rates and not directly linking abortions and the crimes committed by individual cohorts missed catching obvious patterns. Yet, even if Donohue and Levitt believe that the correct approach is to link crimes committed by all ages with their aggregate "effective abortion rate," sensible minor adjustments such as allowing the share of crime committed by different ages to vary across states and years rather than assuming that the weights are constant reverses the sign on their estimates.

This is not to suggest that the hypothesis provided by Bouza-Morgentaler-Donohue-Levitt is not plausible, but at least that it is not the most important part of the story. Abortion can eliminate unwanted children and can benefit many women, but it can also make other women who are unable to bring themselves to have an abortion worse-off and more likely to have out-of-wedlock births. Like many laws there appear to both winners and losers, and here the affect appears to be a net reduction in human capital. 


\section{Bibliography}

Akerlof, George A., Janet L. Yellen, and Michael L. Katz, "An Analysis of Out-of-Wedlock Childbearing in the United States," Quarterly Journal of Economics, May 1996: 277317.

Becker, Gary, A Treatise on the Family, (Chicago, Il.: University of Chicago Press, 1981).

Bouza, Anthony V., The Polic Mystique: An Insider's Look at Cops, Crime, and the Criminal Justice System (New York, NY: Plenum Press, 1990).

Bronars, Stephen G. and Jeff Grogger, "The Economic Consequences of Unwed Motherhood: Using Twins as a Natural Experiment," American Economic Review, Vol. 84, 1994:1141-1156.

Donohue, John J. and Steven Levitt, "The Impact of Legalizing Abortion on Crime Rates," Quarterly Journal of Economics, May 2001, forthcoming.

Donohue, John J. and Peter Siegelman, "Allocating Resources among Prison and Social Programs in the Battle against Crime," Journal of Legal Studies, Vol. 27, January 1998: 1-44.

Joyce, Ted, “Did Legalized Abortion Lower Crime?’Baruch College Working Paper, May 2001.

Plassmann, Florenz, and T. Nicolaus Tideman, "Does the Right to Carry Concealed Handguns Deter Countable Crimes?: Only a Count Analysis can say," Journal of Law and Economics, October 2001: forthcoming.

Grossman, Michael and Theodore Joyce, "Unobservables, Pregnancy Resolutions, and Birth Weight Production Functions in New York City," Journal of Political Economy, October 1990: 983-1007.

Grossman, Michael; Frank J. Chaloupka; and Charles C. Brown, "The Demand for Cocaine by Young Adults: A Rational Addiction Approach,” NBER Working Paper, July 1996.

Gruber, Jonathan, P.B. Levine, and D. Staiger, “Abortion Legalization and Child Living Circumstances: Who is the 'Marginal Child'?" Quarterly Journal of Economics, May 1999: 263-291.

Kahan, Dan, "Social Influence, Social Meaning, and Deterrence," Virginia Law Review, Vol. 83 (1997): 349-395.

Lott, John R., Jr., "Juvenile Delinquency and Education: A Comparison of Public and Private Provision," International Review of Law and Economics, Vol.7, no. 2, December 1987: 163-175.

Lott, John R., Jr., More Guns, Less Crime: Understanding Crime and Gun Control Laws, (Chicago, Illinois: University of Chicago Press, second edition, 2000).

Marvell, Thomas, and Carlisle Moody, "Prison Population Growth and Crime Reduction," Journal of Quantitative Criminology, Vol. 10 (1994): 109-140.

Miller, Ted; Mark Cohen, and Shelli Rossman, "Victim Costs of Violent Crime and Resulting Injuires," Health Affairs, Vol. 12 (1993) : 186-197. 
Morgentaler, Henry, "Message From Henry," http://prochoice.about.com/newsissues/ prochoice/gi/dynamic/offsite.htm?site=http://www.morgentaler.ca/, 1998.

Will, George F., “More Abortions, Fewer Crimes?” Newsweek, April 30, 2001, p. 84. 


\section{Figure 1: Timing of Changes in Murder Rates for Different Age Cohorts Using Data for the Entire United States}

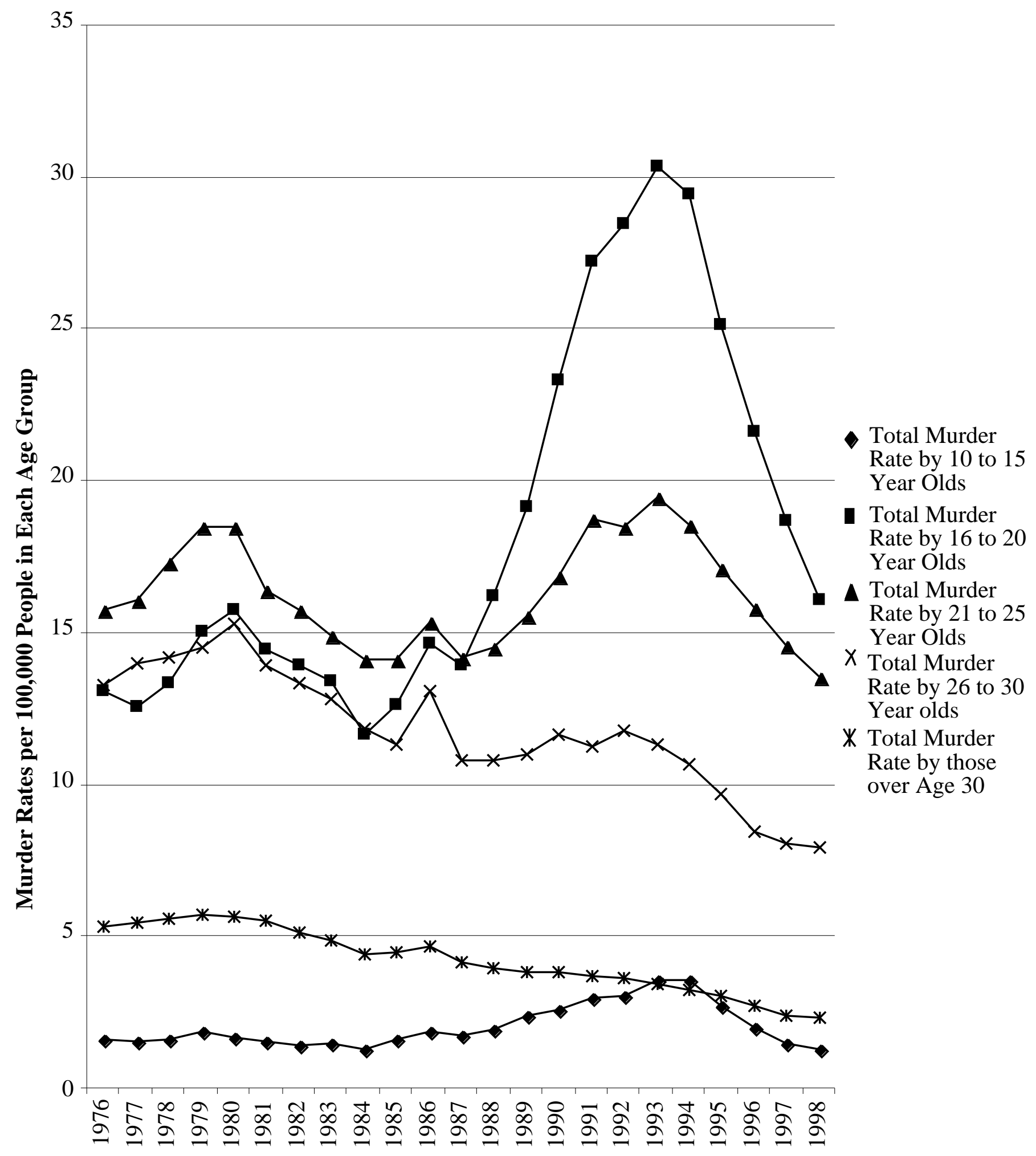

Year 
Figure 2: Comparing "Early" versus "Late" Legalizing States

A) Timing of Changes in Murder Rates for Murderers Who are 10 to 15 Year Old

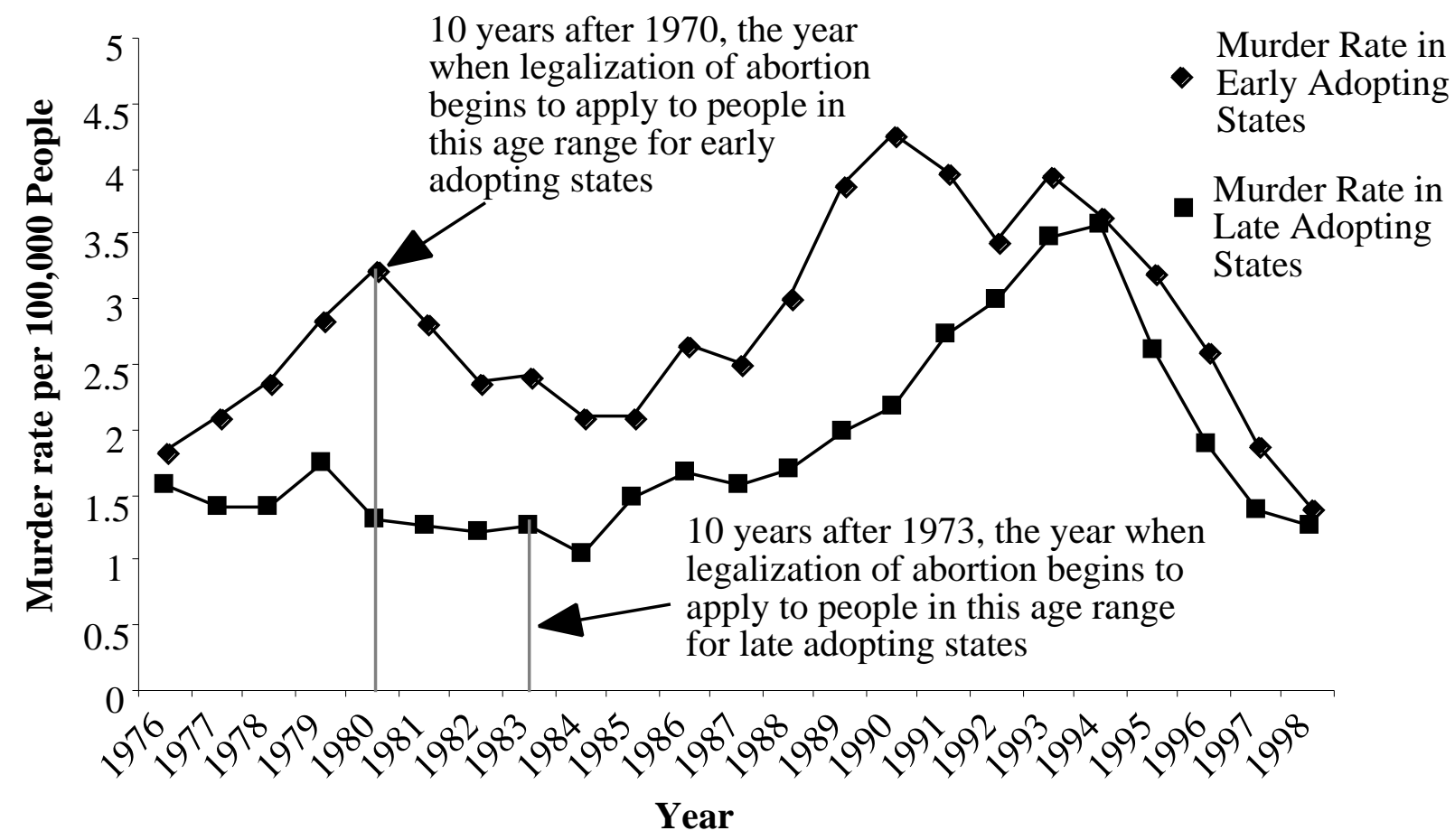

B) Timing of Changes in Murder Rates for Murderers Who are 16 to 20 Year Olds

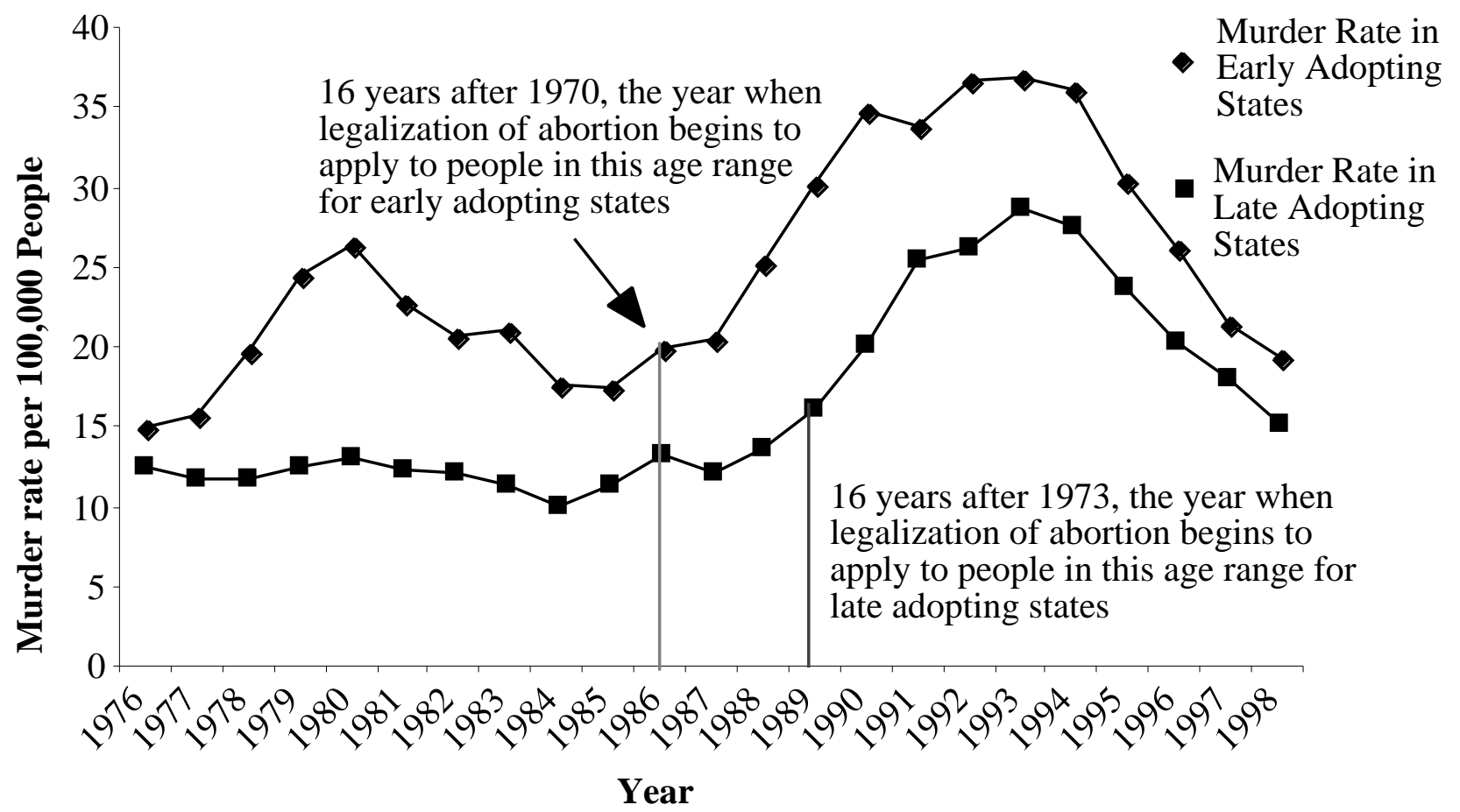




\section{C) Timing of Changes in Murder Rates for Murderer who are 21 to 25 Year Olds}

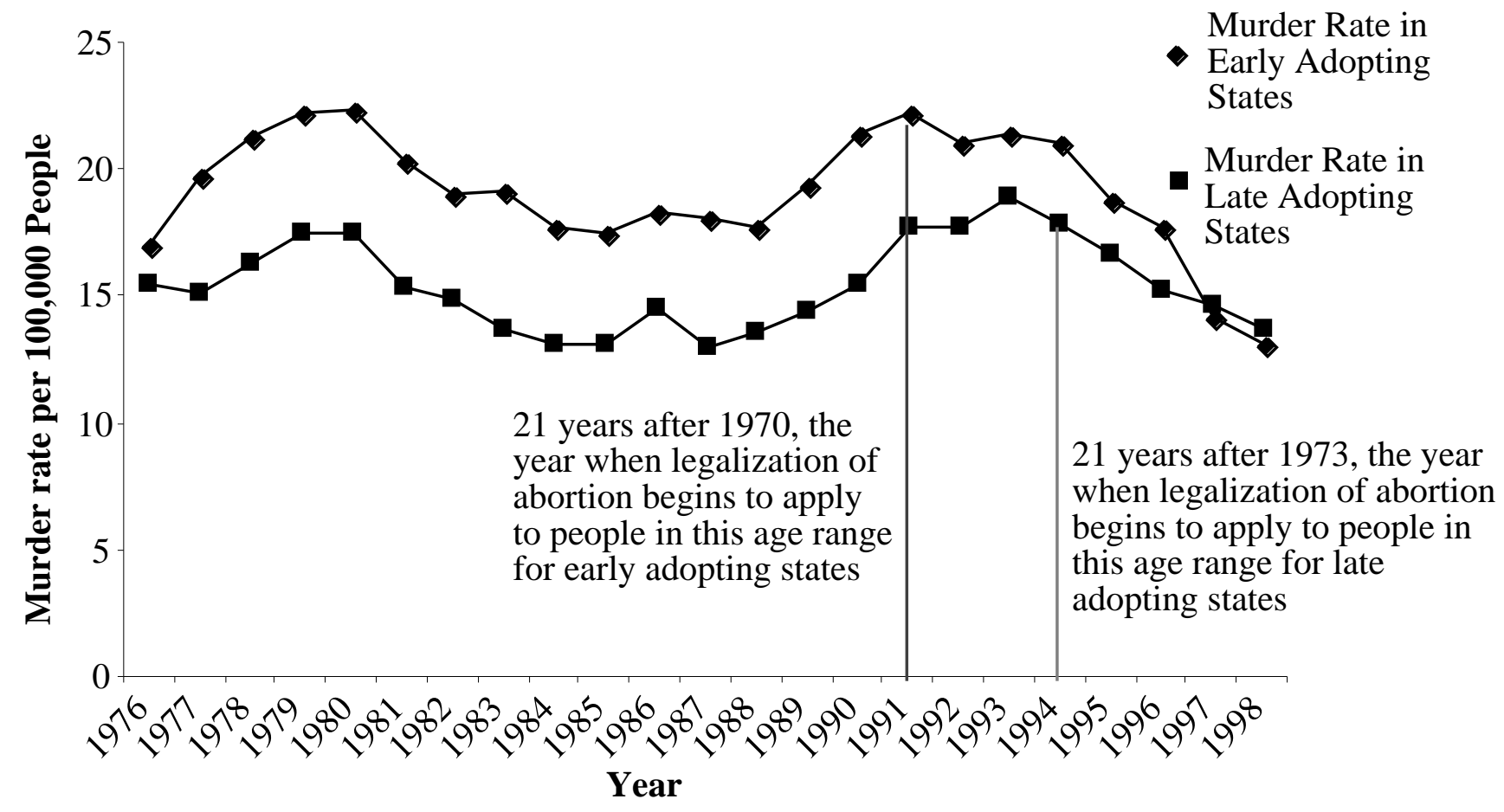

D) Timing of Change in Murder Rates for Murderers Who are 26 to 30 Year Olds

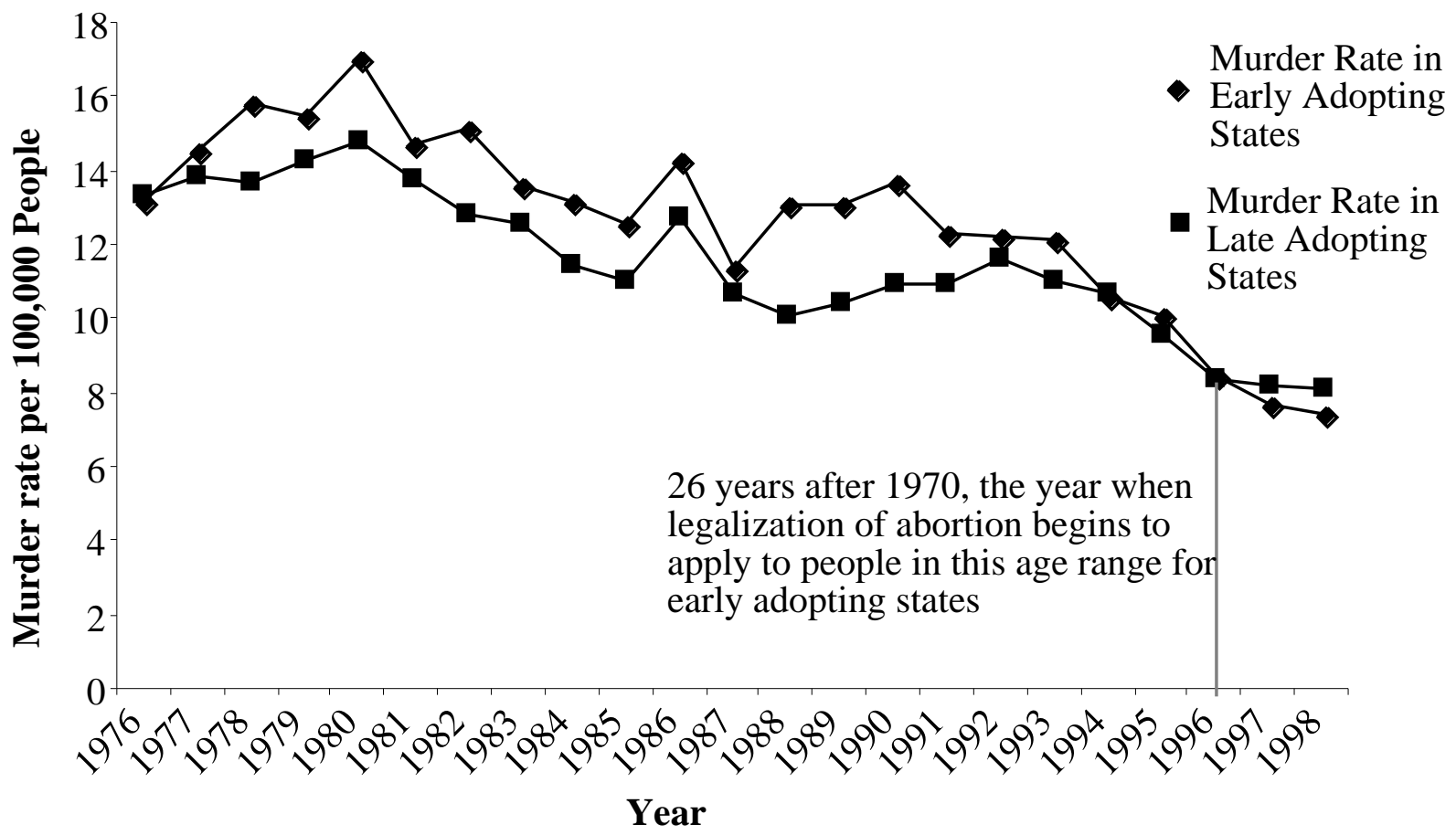


E) Timing of Changes in Murder Rates for Murderers Whose Ages are Unknown

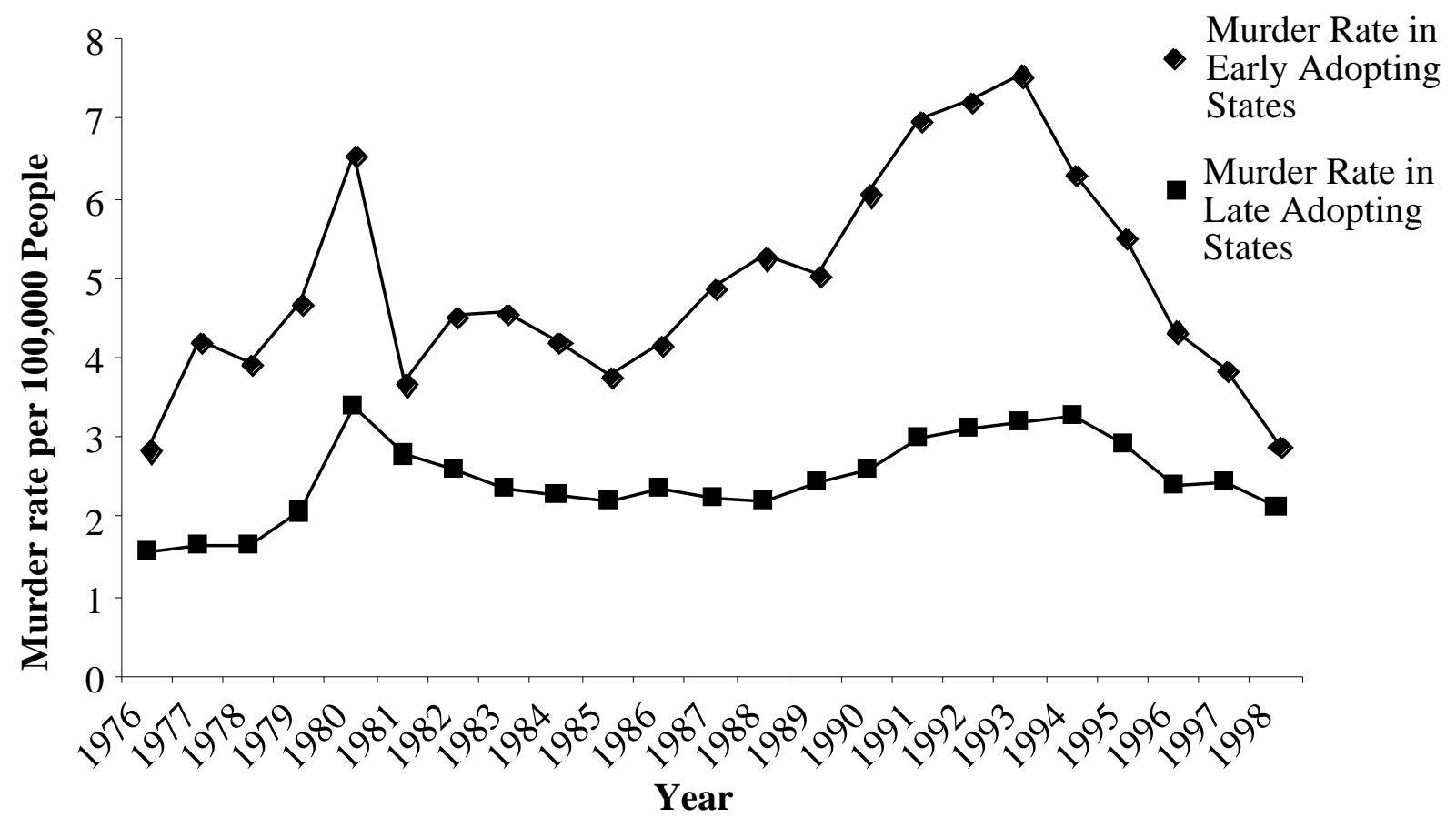


Figure 3: Tracing Cohorts Over Time

A) Following Cohort Murder Rates for Those Born Immediately Before and After the Legalization of Abortion -- States that Legalized Abortion in 1970

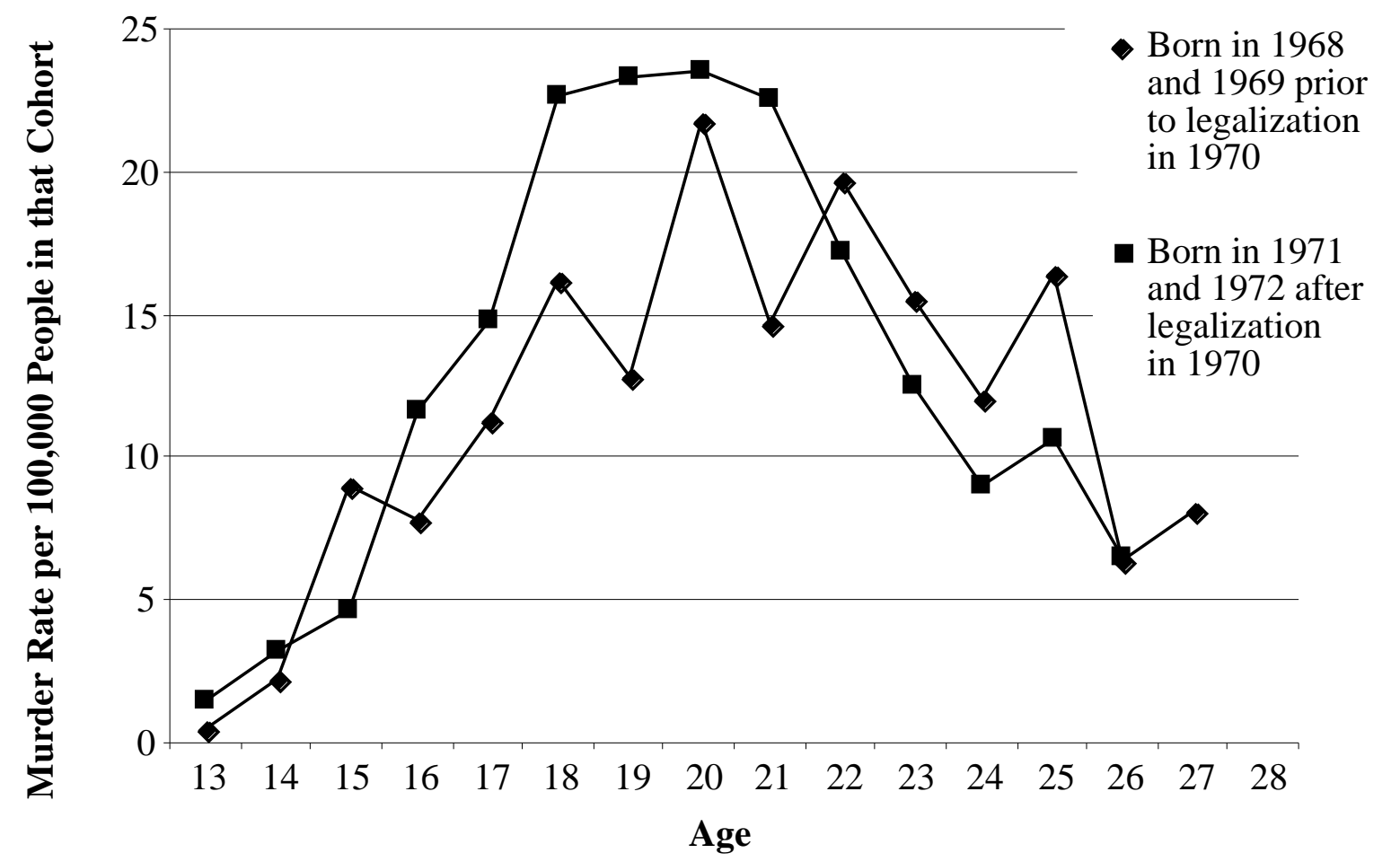

B) Following Cohort Murder Rates for Those Born Immediately Before and After the Legalization of Abortion -- 45 States and the District of Columbia that Legalized Abortion in January 1973

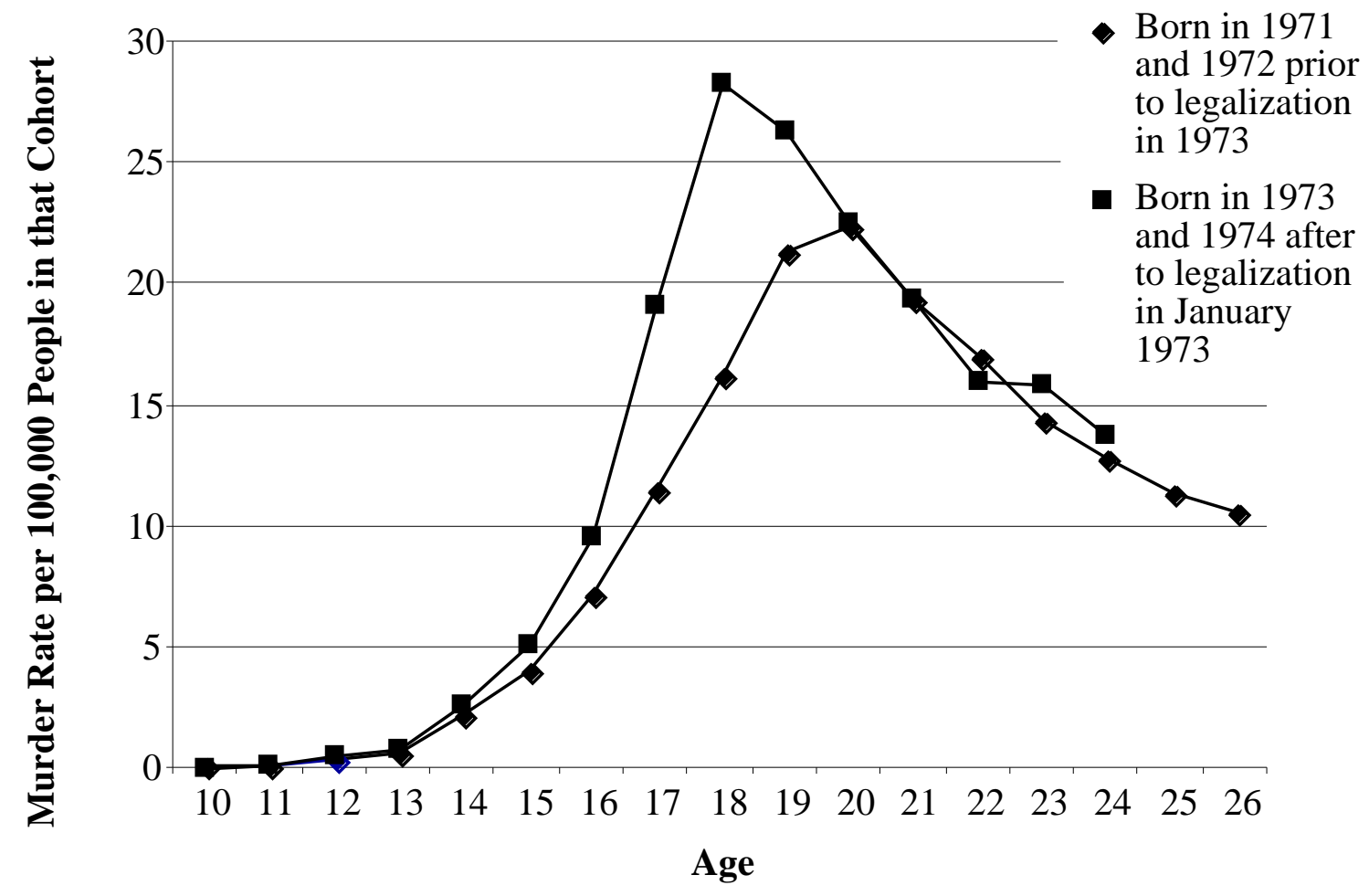


Figure 4: Comparing the Change in Murder Rates by Men and Women

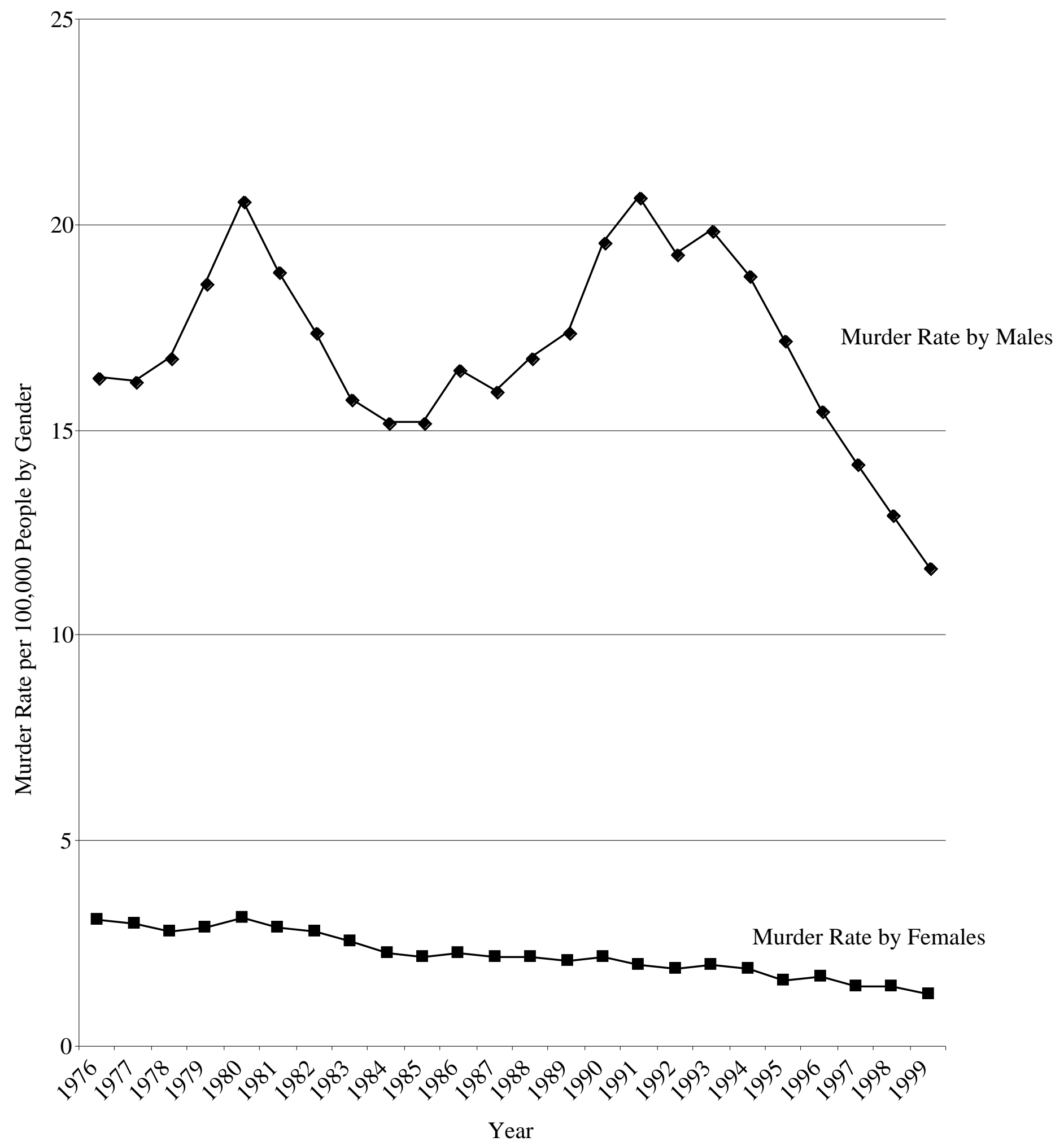




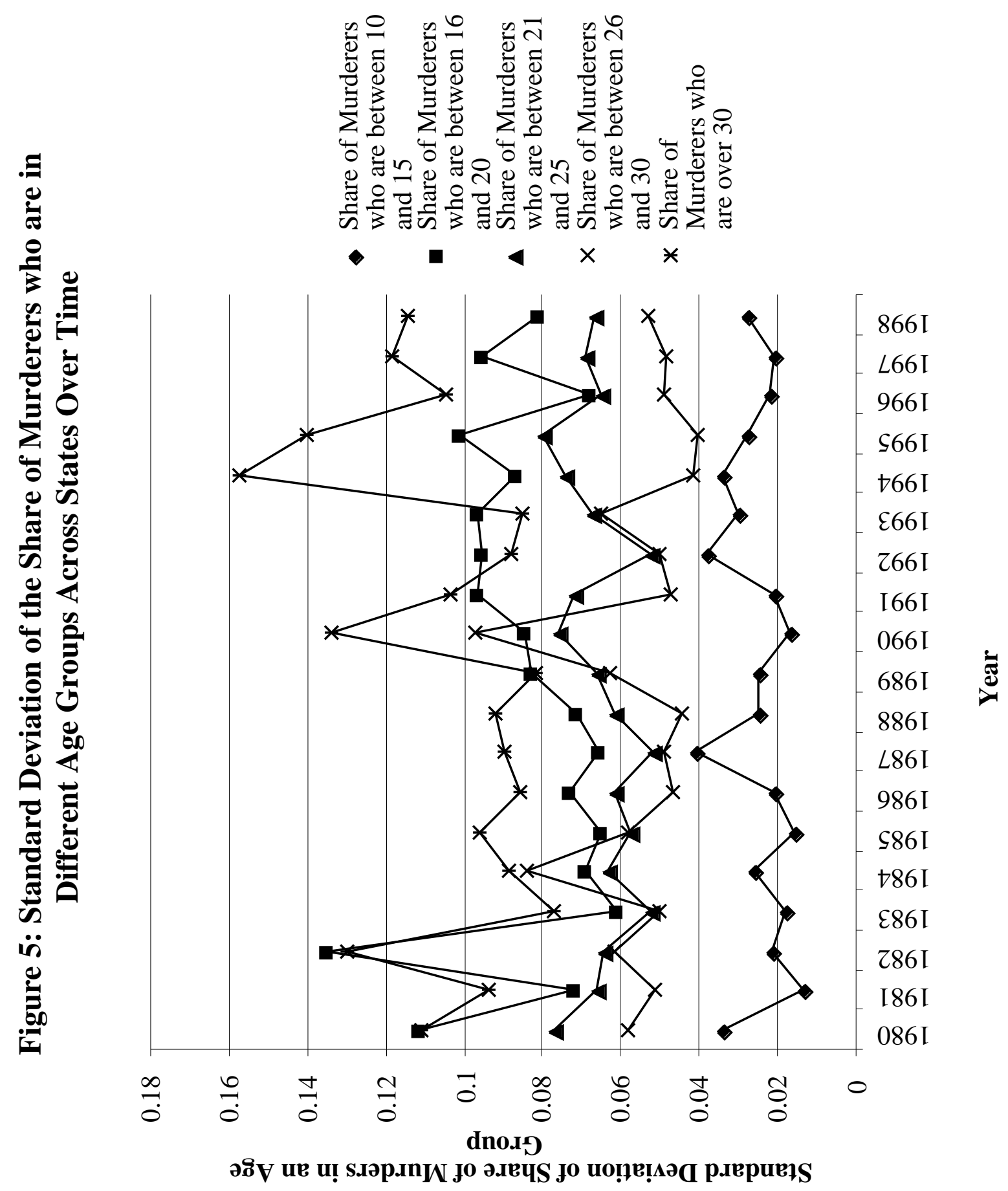


Appendix Figure A1: Tracing Cohorts Over Time By Using a Four Year Period on Either Side of the Legalization of Abortion

A) Following Cohort Murder Rates for Those Born Immediately Before and After the Legalization of Abortion -- States that Legalized Abortion in 1970

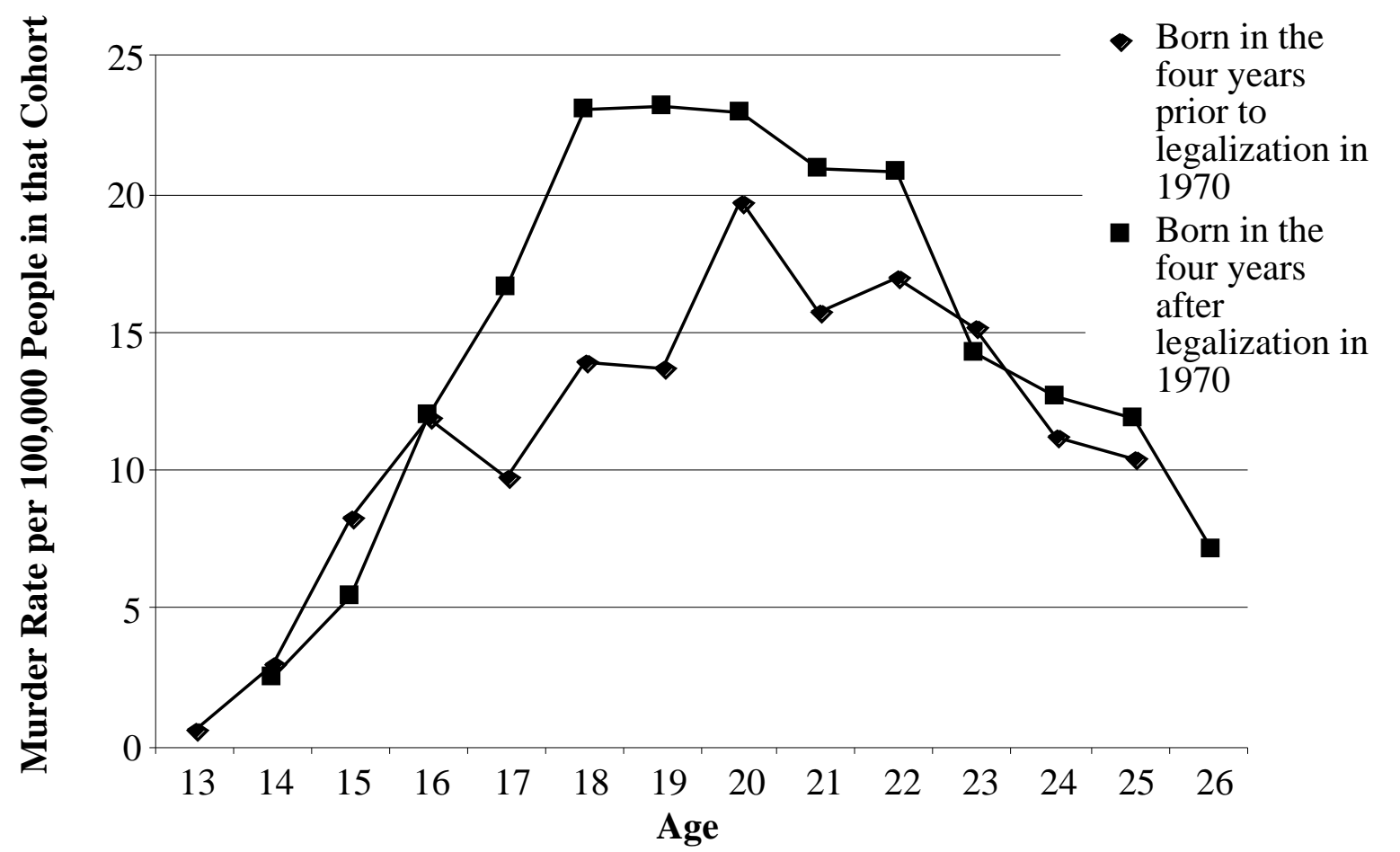

B) Following Cohort Murder Rates for Those Born Immediately Before and After the Legalization of Abortion -- 45 States and the District of Columbia that Legalized Abortion in January 1973

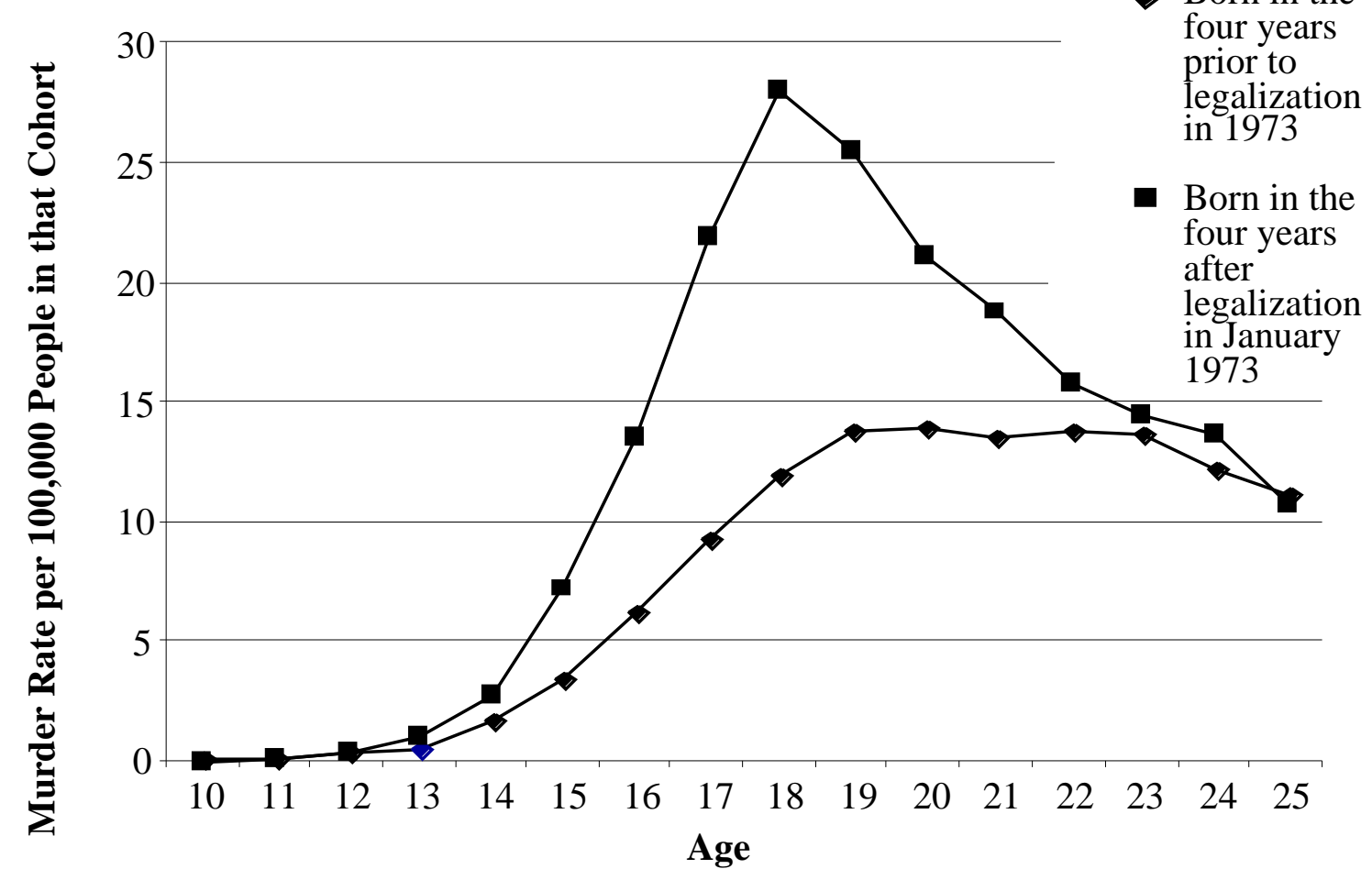


Appendix Figure A2:

The Distribution of Observations

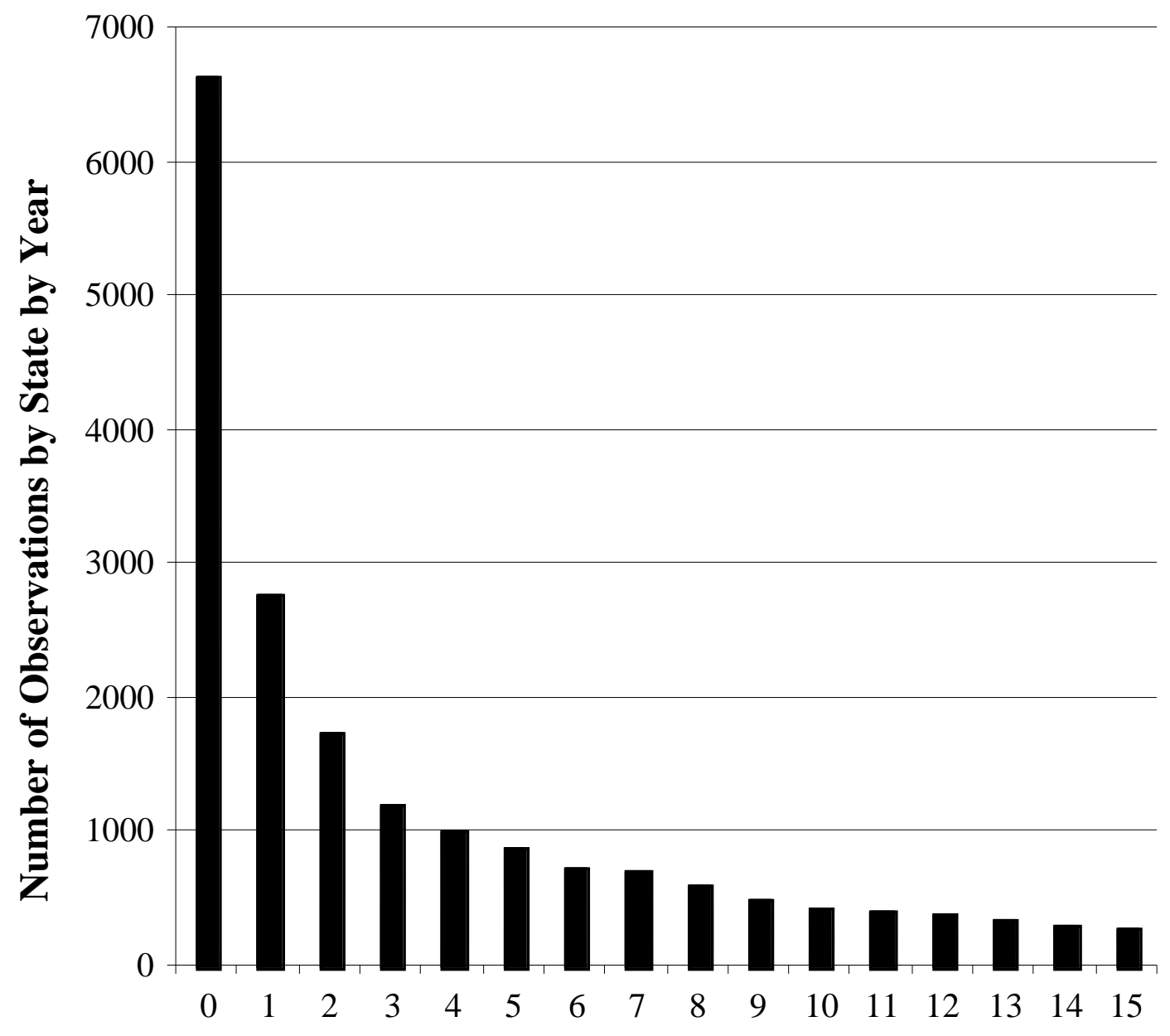

Number of Murderers by Year of Age between 10 and 30 Years of Age 
Table 1: Comparing Abortion Rates for States Where Abortions were "Legal" (in bold) Versus Those where Abortions Could be Done When the Life or Health of the Mother is Endanger

\begin{tabular}{|c|c|c|c|c|c|c|c|}
\hline \multicolumn{2}{|c|}{1969} & \multicolumn{2}{|c|}{1970} & \multicolumn{2}{|c|}{1971} & \multicolumn{2}{|c|}{1972} \\
\hline State & $\begin{array}{l}\text { Number of } \\
\text { abortions } \\
\text { per } 1,000 \\
\text { live births }\end{array}$ & State & $\begin{array}{l}\text { Number of } \\
\text { abortions } \\
\text { per } 1,000 \\
\text { live births }\end{array}$ & State & $\begin{array}{l}\text { Number of } \\
\text { abortions } \\
\text { per } 1,000 \\
\text { live births }\end{array}$ & State & $\begin{array}{l}\text { Number of } \\
\text { abortions } \\
\text { per } 1,000 \\
\text { live births }\end{array}$ \\
\hline California & 35 & Alaska & 120 & Alabama & 7 & Alabama & 19 \\
\hline Colorado & 25 & California & 172 & Alaska & 160 & Alaska & 169 \\
\hline Georgia & 2 & Colorado & 53 & Arizona & 20 & Arizona & 7 \\
\hline Maryland & 31 & D.C. & 268 & Arkansas & 18 & Arkansas & 24 \\
\hline & & Delaware & 55 & California & 344 & California & 420 \\
\hline & & Georgia & 7 & Colorado & 101 & Colorado & 136 \\
\hline & & Hawaii & 204 & Connecticut & 16 & Connecticut & 66 \\
\hline & & Maryland & 101 & D.C. & 703 & D.C. & 1801 \\
\hline & & New Mexico & 73 & Delaware & 114 & Delaware & 151 \\
\hline & & New York & 534 & Georgia & 17 & Florida & 42 \\
\hline & & North Carolina & 13 & Hawaii & 261 & Georgia & 29 \\
\hline & & Oregon & 199 & Kansas & 277 & Hawaii & 295 \\
\hline & & South Carolina & 8 & Maryland & 145 & Kansas & 369 \\
\hline & & Virginia & 14 & Massachusetts & 33 & Maryland & 178 \\
\hline & & Washington & 83 & Mississippi & 2 & Massachusetts & 41 \\
\hline & & & & New Mexico & 219 & Mississippi & 1 \\
\hline & & & & New York & 927 & Nebraska & 34 \\
\hline & & & & North Carolina & 46 & New Mexico & 291 \\
\hline & & & & Oregon & 206 & New York & 1183 \\
\hline & & & & Pennsylvania & 36 & North Carolina & 94 \\
\hline & & & & South Carolina & 14 & Oregon & 228 \\
\hline & & & & Vermont & 1 & Pennsylvania & 52 \\
\hline & & & & Virginia & 46 & South Carolina & 17 \\
\hline & & & & Washington & 265 & Tennessee & 0 \\
\hline & & & & Wisconsin & 65 & Vermont & 32 \\
\hline & & & & & & Virginia & 60 \\
\hline & & & & & & Washington & 377 \\
\hline & & & & & & Wisconsin & 116 \\
\hline
\end{tabular}


Table 2: Re-constructing Donohue and Levitt's "Effective Abortion Rate" for Murder Over the Period from 1985 to 1997 (Sample limited to period examined by Donohue and Levitt. The Regressions are Weighted Least Squares using state and year panel data. Control variables correspond to Columns 5 and 6 in Donohue and Levitt's Table 4.)

\begin{tabular}{|c|c|c|}
\hline $\begin{array}{l}\text { Different Measures of "Effective Abortion Rate": } \\
\text { Using National Average Weights for } 1985 \text { or State and Year Specific Weights } \\
\text { Assuming that No Abortions Occurred when not defined as "Legal" by } \\
\text { Donohue and Levitt or Using CDC Abortion Data for All Years }\end{array}$ & $\begin{array}{l}\text { Using the } \\
\text { Natural Log of } \\
\text { the UCR } \\
\text { Murder Rate } \\
\text { Data as } \\
\text { employed by } \\
\text { Donohue and } \\
\text { Levitt } \\
\text { (1) }\end{array}$ & \begin{tabular}{|} 
Using the \\
Natural Log of \\
the \\
Supplemental \\
Homicide \\
Report Measure \\
of Murder \\
Offender Rate \\
(2)
\end{tabular} \\
\hline
\end{tabular}

A) Results correspond to Donohue and Levitt's Table 4, column 5

\begin{tabular}{|l|l|c|c|}
\hline 1 & $\begin{array}{l}\text { Replicating the estimate that Donohue and Levitt report using the Effective } \\
\text { Abortion Rate supplied by them }\end{array}$ & -0.108 & -0.135 \\
\hline 2 & $\begin{array}{l}\text { Effective Abortion Rate with 1985 national average weights using ages 9 to } \\
\text { 28 with zeros for all state/years where abortion on demand was not legal }\end{array}$ & -0.055 & $(1.5714)$ \\
\hline 3 & $\begin{array}{l}\text { Effective Abortion Rate with 1985 national average weights using ages 9 to } \\
\text { 28 and all abortion data }\end{array}$ & -0.042 & $(1.8500)$ \\
\hline 4 & $\begin{array}{l}\text { Effective Abortion Rate with state and year specific weights using all } \\
\text { abortion data }\end{array}$ & $\begin{array}{c}-0.065 \\
(1.2353)\end{array}$ & $(1.7105)$ \\
\hline
\end{tabular}

B) Results correspond to Donohue and Levitt's Table 4, column 6

\begin{tabular}{|l|l|c|c|}
\hline 5 & $\begin{array}{l}\text { Replicating the estimate that Donohue and Levitt report using the Effective } \\
\text { Abortion Rate supplied by them }\end{array}$ & $\begin{array}{c}-0.121 \\
(2.5745)\end{array}$ & $\begin{array}{c}-0.126 \\
(2.3774)\end{array}$ \\
\hline 6 & $\begin{array}{l}\text { Effective Abortion Rate with 1985 national average weights using ages 9 to } \\
28 \text { with zeros for all state/years where abortion on demand was not legal }\end{array}$ & -0.038 & -0.039 \\
& $(0.9744)$ & $(0.8478)$ \\
\hline 7 & $\begin{array}{l}\text { Effective Abortion Rate with 1985 national average weights using ages 9 to } \\
28 \text { and all abortion data }\end{array}$ & -0.023 & -0.031 \\
$(0.6216)$ & $(0.7381)$ \\
\hline 8 & $\begin{array}{l}\text { Effective Abortion Rate with state and year specific weights using all } \\
\text { abortion data }\end{array}$ & $\begin{array}{c}0.023 \\
(1.5333)\end{array}$ & $(1.5789)$ \\
\hline
\end{tabular}


Table 3: Relationship between Abortion and Murders using Poisson regressions (Coefficients are Incident Rate Ratios, with absolute z-statistics reported in parentheses. Values of the coefficients greater than one show the percent increase in crime, while values less than one indicate the percent decline. The demographics and fixed age, state, and year effects are not reported)

Variable

Number of abortions during the year in which people of that age were born $/ 1000$

Dummy Variable for whether abortions are legal in a state

$\ln$ (Number of abortions during the year in which people of that age were born /1000)

Population in state that is the age of the murders

$\ln$ (Population in state that is the age of the murders)

Population density per square mile in state

$\ln$ (Population density in state)

Number of people in prison

Number of people in prison lagged one year

$\ln$ (Number of people in prison)

Execution rate

Arrest rate for Murder

Arrest rate for Murder lagged one year

Arrest rate for Violent Crime

Unemployment rate

Poverty rate

Per Capita Income

Per Capita Income Maintanence

Per Capita Unemployment Insurance Payments

Per Capita Retirement Payments for those over age 65

Percent change in the number of murderers from the difference in the annual Change in the number of murderers in the years before and after the change in the law (annual rate of change after the law - annual rate of change before the law)

$$
\begin{gathered}
\text { (F-statistic in parentheses) } \\
\text { Log Likelihood } \\
\text { Chi-Square }
\end{gathered}
$$

Number of observations
Number of murderers by age by state by year

$\begin{array}{cccc}1 & 2 & 3 & 4 \\ 1.00023 & 1.00018 & 1.00019 & 1.00019 \\ (40.817) & (26.732) & (27.008) & (27.165)\end{array}$

1.0730

. .

1.034

$\cdots$

$\cdots$

$\cdots$

9.914)

$\begin{array}{cccc}1 & 1 & 1 & 1 \\ (29.005) & (28.920) & (28.850) & (40.755)\end{array}$

$(51.898)$

- .

. .
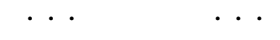

$\cdots$

1.0687

$1.00046 \quad 1.00054$

1.00052

1.00046

(4.632)

(5.419)

(5.168)

(4.596)

...

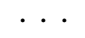

...

.999995

(24.392)

..

.999995

(24.861)

.999995

(21.937)

.999994

(25.708)

..

...

...

.7412

(17.042)

.6352

.4191

.5723

.4223

.3381

(1.082)

(1.587)

(2.173)

(1.551)

(1.922)

...

...

.9998

(2.916)

.99966

(4.741)

(3.129)

.9997

(4.125)

... . .

$\ldots \quad \ldots$

...

.9995

(2.683)

.9897

.9903

(3.328)

(3.144)

.9893

(3.435)

.9998

1.0003

1.000179

(0.121)

(0.111)

(0.221)

(9.801)

1.00005

1.00007

(11.520)

.9994

.9991

(6.906)

(6.607)

1.00053

1.0004

(4.554)

1.00064

(4.421)

(3.184)

(5.238)

.9997

.9997

(12.463)

(16.706)

(12.805)

.9907

(3.013)

.99992

(0.055)

1.00006

(9.850)

.9992

(6.249)

1.0006

(4.574)

.9998

(11.627)

...

. .

.9994

(0.209)

.9977

(1.628)

1.00008

(12.270)

.9983

(14.150)

1.00042

(3.475)

.99990

-1.8 percent -2.5 percent -2.3 percent -1.9 percent -1.0 percent

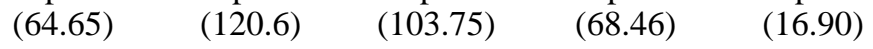

$\begin{array}{cccccc}-69,835 & -53,719 & -53,871 & -52,542 & -54,014 & -53,427 \\ 1511341 & 1268428 & 1266061 & 1255447 & 1267838 & 1269011 \\ 26,448 & 21,480 & 21,411 & 21,319 & 21,480 & 21,480\end{array}$




\section{Table 4: Sensitivity of Abortion Coefficients Using the Alternative Specifications Used by Donohue and Levitt (Only the Incident Rate Ratios for the abortion effects are reported.)}

\author{
Specification
}

1) Linear value of Abortion

(Corresponding to Specification 2 in Table 3)

$$
\text { Baseline }
$$

Exclude New York

Exclude California

Exclude District of Columbia

Exclude New York, California, District of Columbia

Adjust abortion rate for nonresidents

Include control for flow of immigrants

Include state-specific trends

include region-year interactions

Include control for overall fertility

Limiting sample to only those ages affected by abortion

(eliminating observations for those over 29 and of unknown age)

Allowing for state specific year fixed effects in addition to the number of abortions and the age specific population

2) Dummy variable for legalizing abortion

(Corresponding to Specification 5 in Table 3)

Baseline

Exclude New York

Exclude California

Exclude District of Columbia

Exclude New York, California, District of Columbia

Adjust abortion rate for nonresidents

Include control for flow of immigrants

Include state-specific trends

include region-year interactions

Include control for overall fertility

Limiting sample to only those ages affected by abortion

(eliminating observations for those over 29 and of unknown age)

Allowing for state specific year fixed effects in addition to the

number of abortions and the age specific population

3) Natural logs of abortion and population variables

(Corresponding to Specification 6 in Table 3)

Baseline

Exclude New York

Exclude California

Exclude District of Columbia

Exclude New York, California, District of Columbia

Adjust abortion rate for nonresidents

Include control for flow of immigrants

Include state-specific trends

include region-year interactions

Include control for overall fertility

Limiting sample to only those ages affected by abortion

(eliminating observations for those over 29 and of unknown age)

Allowing for state specific year fixed effects in addition to the

$\ln$ (number of abortions) and the $\ln$ (age specific population)
Coefficient for the number of abortions by in-state residents (divided by 1000) except where noted Incident Rate Ratio

Coefficient

$\begin{array}{lc}1.00183 & 26.732 \\ 1.00359 & 37.344 \\ 1.00146 & 16.391 \\ 1.00181 & 26.383 \\ 1.01210 & 47.513 \\ 1.00189 & 20.646 \\ 1.00086 & 11.671 \\ 1.00186 & 26.844 \\ 1.00175 & 23.245 \\ 1.00115 & 6.273 \\ 1.00244 & 27.488 \\ & \\ 1.00086 & 9.336\end{array}$

1.073

9.914

1.071

9.529

1.063

8.285

1.072

9.815

1.060

7.689

...

1.074

...

1.074

10.108

1.070

10.027

9.443

1.044

2.590

1.127

16.460

1.0525

6.017

1.0343

51.898

1.0378

54.470

1.0354

46.256

1.0343

51.691

1.0405

48.966

1.0429

54.007

1.023

33.65

1.0342

51.570

1.0344

50.613

1.0067

4.591

1.0309

40.683

1.0147

15.811 
Table 5: Range of Coefficient Estimates for the number of abortions by in-state residents (/1000) for Different Linear Combinations of the Control Variables (Coefficients are Incident Rate Ratios. Only the range of values for the abortion variable are reported.)

Using Fixed Year, State, and Age Effects $\mathrm{n}=1024$

Incident Rate Ratio Coefficient Range

1) Linear value of Abortion

(Corresponds to Specification 2 in Table 3)

$\begin{array}{lll}\text { High } & 1.0028 & 45.741 \\ \text { Median } & 1.0018 & 25.718 \\ \text { Low } & 1.0014 & 21.632\end{array}$

Low

1.0014

2) Dummy variable for legalizing abortion

(Corresponds to Specification 5 in Table 3)

\begin{tabular}{|c|c|c|c|c|}
\hline High & 1.087 & 12.485 & 1.0859 & 12.3193 \\
\hline Median & 1.074 & 10.513 & 1.0744 & 10.5838 \\
\hline Low & 1.069 & 9.700 & 1.0700 & 9.851 \\
\hline
\end{tabular}

3) Natural logs of abortion and population variables

(Corresponds to Specification 6 in Table 3)

High

1.0275

46.332

Median

1.0257

42.781

Low

1.0220
1.0269

44.2698

Using Fixed Year, State, and Age Effects and Individual State Time Trends $n=1024$

Incident Rate Ratio z-statistic Range Coefficient Range
1.0026
1.0019

1.0013

25.223

18.232

1.0255

41.7953

1.0172 
Table 6: Breaking Down the Impact of Abortion by the Age of the Criminal (Using Poisson regressions and only reporting the interactions for those age groups that are young enough to be effected by the legalization of abortion. All coefficients are Incident Rate Ratios. The specifications correspond to columns 2, 5, and 6 in Table 3, though the other variables are not reported here.)

\begin{tabular}{|c|c|c|c|c|c|c|}
\hline & \multicolumn{2}{|c|}{$\begin{array}{l}\text { Number of Abortions } / 1000 \\
\text { Interacted with Age Dummies }\end{array}$} & \multicolumn{2}{|c|}{$\begin{array}{c}\text { Legalization of Abortion } \\
\text { Dummy Interacted with Age } \\
\text { Dummies }\end{array}$} & \multicolumn{2}{|c|}{$\begin{array}{c}\text { Natural Log of the Number } \\
\text { of Abortions Interacted with } \\
\text { Age Dummies }\end{array}$} \\
\hline & \multicolumn{2}{|c|}{$\begin{array}{l}\text { Specification based upon } \\
\text { Column } 2 \text { in Table } 3\end{array}$} & \multicolumn{2}{|c|}{$\begin{array}{c}2 \\
\text { Specification based upon } \\
\text { Column } 5 \text { in Table } 3\end{array}$} & \multicolumn{2}{|c|}{$\begin{array}{c}3 \\
\text { Specification based upon } \\
\text { Column } 6 \text { in Table } 3\end{array}$} \\
\hline & $\begin{array}{c}\text { Incident Rate } \\
\text { Ratio }\end{array}$ & $\begin{array}{l}\text { Absolute Z- } \\
\text { statistic }\end{array}$ & $\begin{array}{c}\text { Incident Rate } \\
\text { Ratio }\end{array}$ & $\begin{array}{l}\text { Absolute Z- } \\
\text { statistic }\end{array}$ & $\begin{array}{c}\text { Incident Rate } \\
\text { Ratio }\end{array}$ & $\begin{array}{l}\text { Absolute z- } \\
\text { statistic }\end{array}$ \\
\hline Age 10 & 0.7999 & 40.919 & 0.598 & 1.604 & 0.7448 & 64.951 \\
\hline Age 11 & 0.8497 & 44.758 & 0.882 & 0.55 & 0.7765 & 66.681 \\
\hline Age 12 & 0.9019 & 48.014 & 1.024 & 0.149 & 0.8104 & 66.003 \\
\hline Age 13 & 0.9572 & 47.086 & 1.288 & 2.374 & 0.8545 & 61.219 \\
\hline Age 14 & 0.9865 & 35.231 & 1.331 & 4.389 & 0.9131 & 46.503 \\
\hline Age 15 & 0.9977 & 11.193 & 1.401 & 7.558 & 0.9738 & 17.627 \\
\hline Age 16 & 1.0033 & 23.146 & 1.306 & 8.076 & 1.0226 & 17.78 \\
\hline Age 17 & 1.0058 & 46.96 & 1.178 & 6.203 & 1.0542 & 46.187 \\
\hline Age 18 & 1.0070 & 60.59 & 1.051 & 2.15 & 1.0726 & 61.852 \\
\hline Age 19 & 1.0068 & 55.359 & 1.055 & 2.638 & 1.0668 & 54.305 \\
\hline Age 20 & 1.0074 & 60.154 & 0.909 & 4.673 & 1.0668 & 50.594 \\
\hline Age 21 & 1.0047 & 27.17 & 0.917 & 3.912 & 1.0373 & 23.384 \\
\hline Age 22 & 1.0042 & 21.984 & 0.979 & 0.939 & 1.0281 & 15.498 \\
\hline Age 23 & 1.0035 & 14.676 & 1.047 & 1.883 & 1.0138 & 6.584 \\
\hline Age 24 & 1.0033 & 11.668 & 1.140 & 4.911 & 1.0043 & 1.783 \\
\hline Age 25 & 1.0037 & 12.337 & 1.227 & 7.489 & 0.9871 & 4.576 \\
\hline Age 26 & 1.0027 & 6.603 & 1.240 & 6.829 & 1.0026 & 0.825 \\
\hline Age 27 & 1.0025 & 4.032 & 1.157 & 4.079 & 1.0077 & 2.252 \\
\hline Age 28 & 1.0039 & 1.977 & 1.272 & 5.252 & 1.0178 & 4.52 \\
\hline Age 29 & 1.0550 & 3.085 & 1.303 & 4.116 & 1.0722 & 15.766 \\
\hline Model chi ${ }^{2}$ & \multicolumn{2}{|c|}{1113906} & \multicolumn{2}{|c|}{1494717} & \multicolumn{2}{|c|}{1235415} \\
\hline Log Likelihood & \multicolumn{2}{|c|}{-130980} & \multicolumn{2}{|c|}{-58773} & \multicolumn{2}{|c|}{-705225} \\
\hline Pseudo $\mathrm{R}^{2}$ & \multicolumn{2}{|c|}{0.8096} & \multicolumn{2}{|c|}{.9271} & \multicolumn{2}{|c|}{.8979} \\
\hline $\begin{array}{c}\text { Number of } \\
\text { Observations }\end{array}$ & \multicolumn{2}{|c|}{21480} & \multicolumn{2}{|c|}{21480} & \multicolumn{2}{|c|}{21480} \\
\hline
\end{tabular}


Table 7: Disaggregating Crime and Abortion Rates by Race (Specifications 2, 5, and 6 from Table 3 serve as the basis of the control variables used here. The number of observations equals 17,372 for the first and third set of specifications and 21,478 for the second set.)

A) Comparing the Racial Composition of Abortions to the Racial and Sex Composition of Murderers

Incident Rate absolute z-statistic

1) Linear value of Abortion

Ratio Coefficient

(Corresponds to Specification 2 in Table 3)

Murders by White Males related to Abortions by White Mothers

1.0022

.9999

15.127

Murders by White Females related to Abortions by White Mothers

1.0046

0.090

Murders by Nonwhite Males related to Abortions by Nonwhite Mothers

1.0078

11.027

Murders by Nonwhite Females related to Abortions by Nonwhite Mothers

5.227

2) Dummy variable for legalizing abortion

(Corresponds to Specification 5 in Table 3)

Murders by White Males related to Abortions by White Mothers

1.1659

12.710

Murders by White Females related to Abortions by White Mothers

1.0795

2.126

Murders by Nonwhite Males related to Abortions by Nonwhite Mothers

1.0422

4.316

Murders by Nonwhite Females related to Abortions by Nonwhite Mothers

1.1700

5.012

3) Natural logs of abortion and population variables

(Corresponds to Specification 6 in Table 3)

Murders by White Males related to Abortions by White Mothers

1.0386

31.149

Murders by White Females related to Abortions by White Mothers

1.0108

2.704

Murders by Nonwhite Males related to Abortions by Nonwhite Mothers

1.0449

36.172

Murders by Nonwhite Females related to Abortions by Nonwhite Mothers

1.0295

7.515

\section{B) Comparing the Racial Composition of Abortions to the Racial Composition of the Victims}

Incident Rate absolute z-statistic

1) Linear value of Abortion

Ratio Coefficient

(Corresponds to Specification 2 in Table 3)

Murders by Whites of Nonwhites related to Abortions by White Mothers

1.0022

5.516

Murders by Whites of Whites related to Abortions by White Mothers

1.0022

13.940

Murders by Nonwhites of Whites related to Abortions by Nonwhite Mothers

1.0015

1.704

Murders by Nonwhites of Nonwhites related to Abortions by Nonwhite Mothers

1.0125

28.306

2) Dummy variable for legalizing abortion

(Corresponds to Specification 5 in Table 3)

Murders by Whites of Nonwhites related to Abortions by White Mothers

1.1482

3.577

Murders by Whites of Whites related to Abortions by White Mothers

1.1599

12.349

Murders by Nonwhites of Whites related to Abortions by Nonwhite Mothers

1.1210

5.102

Murders by Nonwhites of Nonwhites related to Abortions by Nonwhite Mothers

.9937

0.628

3) Natural logs of abortion and population variables

(Corresponds to Specification 6 in Table 3)

Murders by Whites of Nonwhites related to Abortions by White Mothers

1.0450

11.888

Murders by Whites of Whites related to Abortions by White Mothers

1.0357

28.581

Murders by Nonwhites of Whites related to Abortions by Nonwhite Mothers

1.0306

11.556

Murders by Nonwhites of Nonwhites related to Abortions by Nonwhite Mothers

1.0534

41.624 
Table 8: Examining the Relationship Between Abortion and Arrest Rates (Using Arrest Rate Data from 1985 to 1996 for 15 to 24 Year Olds by Age by State by Year)

\begin{tabular}{|c|c|c|}
\hline Specification & $\begin{array}{l}\text { Regular } \\
\text { Coefficients } \\
\text { for OLS }\end{array}$ & $\begin{array}{l}\text { Absolute t- } \\
\text { statistics for } \\
\text { OLS }\end{array}$ \\
\hline \multicolumn{3}{|l|}{ 1) Arrests for Violent Crime } \\
\hline $\begin{array}{l}\text { Number of Arrests by Age on Abortions in Birth Year } \\
\text { Poisson Regressions corresponding to Specification } 2 \text { Table } 3 \\
\text { Fixed Effects for Age, State, and Year }\end{array}$ & 1.00018 & 10.87 \\
\hline $\begin{array}{l}\text { Number of Arrests by Age on Abortions in Birth Year } \\
\text { Poisson Regressions corresponding to Specification } 2 \text { Table } 3 \\
\text { Fixed Effects for Age, State, Year, and Individual Trend by State }\end{array}$ & 1.00014 & 7.97 \\
\hline $\begin{array}{l}\text { Number of Arrests by Age on Natural Log of Abortions in Birth Year } \\
\text { Poisson Regressions corresponding to Specification } 6 \text { Table } 3 \\
\text { Fixed Effects for Age, State, and Year }\end{array}$ & .9996 & 2.403 \\
\hline $\begin{array}{l}\text { Number of Arrests by Age on Natural Log of Abortions in Birth Year } \\
\text { Poisson Regressions corresponding to Specification } 6 \text { Table } 3 \\
\text { Fixed Effects for Age, State, Year, and Individual Trend by State }\end{array}$ & .9995 & 2.846 \\
\hline $\begin{array}{l}\text { Natural log of Arrests by Age on the Abortion Rate per Live Birth in Birth Year } \\
\text { (x100) } \\
\text { Weighted OLS with the other control variables used in Specification } 2 \text { Table } 3 \\
\text { Fixed Effects for Age, State, and Year to correspond to Donohue and Levitt's } \\
\text { Table } 7 \text { Column } 1\end{array}$ & .00023 & 8.850 \\
\hline $\begin{array}{l}\text { Natural log of Arrests by Age on the Abortion Rate per Live Birth in Birth Year } \\
\text { (x100) } \\
\text { Weighted OLS with the other control variables used in Specification } 2 \text { Table } 3 \\
\text { Fixed Effects Year and separate Age Fixed Effects by State to correspond to } \\
\text { Donohue and Levitt's Table } 7 \text { Column } 3\end{array}$ & .00021 & 8.591 \\
\hline \multicolumn{3}{|l|}{ 2) Arrests for Murder } \\
\hline $\begin{array}{l}\text { Number of Arrests by Age on Abortions in Birth Year } \\
\text { Poisson Regressions corresponding to Specification } 2 \text { Table } 3 \\
\text { Fixed Effects for Age, State, and Year }\end{array}$ & 1.00083 & 8.390 \\
\hline $\begin{array}{l}\text { Number of Arrests by Age on Abortions in Birth Year } \\
\text { Poisson Regressions corresponding to Specification } 2 \text { Table } 3 \\
\text { Fixed Effects for Age, State, Year, and Individual Trend by State }\end{array}$ & 1.00099 & 9.805 \\
\hline $\begin{array}{l}\text { Number of Arrests by Age on Natural Log of Abortions in Birth Year } \\
\text { Poisson Regressions corresponding to Specification } 6 \text { Table } 3 \\
\text { Fixed Effects for Age, State, and Year }\end{array}$ & 1.0073 & 7.838 \\
\hline $\begin{array}{l}\text { Number of Arrests by Age on Natural Log of Abortions in Birth Year } \\
\text { Poisson Regressions corresponding to Specification } 6 \text { Table } 3 \\
\text { Fixed Effects for Age, State, Year, and Individual Trend by State }\end{array}$ & 1.0080 & 8,544 \\
\hline $\begin{array}{l}\text { Natural log of Arrests by Age on the Abortion Rate per Live Birth in Birth Year } \\
\text { (x100) } \\
\text { Weighted OLS with the other control variables used in Specification } 2 \text { Table } 3 \\
\text { Fixed Effects for Age, State, and Year -- Corresponding regressions are not } \\
\text { reported in Donohue and Levitt's paper }\end{array}$ & .00042 & 9.285 \\
\hline $\begin{array}{l}\text { Natural log of Arrests by Age on the Abortion Rate per Live Birth in Birth Year } \\
\text { (x100) } \\
\text { Weighted OLS with the other control variables used in Specification } 2 \text { Table } 3 \\
\text { Fixed Effects for Age, State, and Year -- Corresponding regressions are not } \\
\text { reported in Donohue and Levitt's paper }\end{array}$ & .00053 & 10.957 \\
\hline
\end{tabular}


3) Arrests for Property Crime

Number of Arrests by Age on Abortions in Birth Year

Poisson Regressions corresponding to Specification 2 Table 3

Fixed Effects for Age, State, and Year

Number of Arrests by Age on Abortions in Birth Year

Poisson Regressions corresponding to Specification 2 Table 3

Fixed Effects for Age, State, Year, and Individual Trend by State

Number of Arrests by Age on Natural Log of Abortions in Birth Year

Poisson Regressions corresponding to Specification 6 Table 3

Fixed Effects for Age, State, and Year

Number of Arrests by Age on Natural Log of Abortions in Birth Year

Poisson Regressions corresponding to Specification 6 Table 3

Fixed Effects for Age, State, Year, and Individual Trend by State

Natural log of Arrests by Age on the Abortion Rate per Live Birth in Birth Year (x100)

Weighted OLS with the other control variables used in Specification 2 Table 3 Fixed Effects for Age, State, and Year to correspond to Donohue and Levitt's Table 7 Column 5

Natural log of Arrests by Age on the Abortion Rate per Live Birth in Birth Year (x100)

Weighted OLS with the other control variables used in Specification 2 Table 3

Fixed Effects Year and separate Age Fixed Effects by State to correspond to

Donohue and Levitt's Table 7 Column 7

\begin{tabular}{|c|c|}
\hline .9999 & 12.955 \\
\hline .9999 & 9.596 \\
\hline .9974 & 30.462 \\
\hline .9975 & 29.192 \\
\hline-.00007 & 3.228 \\
& \\
\hline .00009 & 5.706 \\
\hline
\end{tabular}


Table 9: The Impact of Abortions on Out-of-Wedlock Births (Again the coefficients are Incident Rate Ratios. Demographics and fixed state and year effects are not reported)

\begin{tabular}{|c|c|c|c|}
\hline \multicolumn{4}{|c|}{ Explaining the Number of Out-of-wedlock Births by State by Year } \\
\hline \multirow[b]{2}{*}{ Variable } & \multicolumn{3}{|c|}{ Coefficients and absolute z-statistics } \\
\hline & 1 & 2 & 3 \\
\hline $\begin{array}{l}\text { Number of in-state abortions during the year in } \\
\text { which people of that age were born /1000 }\end{array}$ & $\begin{array}{l}1.000074 \\
(4.211)\end{array}$ & & $\ldots$ \\
\hline $\begin{array}{l}\text { Dummy Variable for whether abortions are legal } \\
\text { in a state }\end{array}$ & & $\begin{array}{l}.9815 \\
(2.035)\end{array}$ & 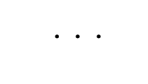 \\
\hline $\begin{array}{l}\ln (\text { Number of abortions during the year in which } \\
\text { people of that age were born /1000) }\end{array}$ & & & $\begin{array}{c}1.000022 \\
(1.864)\end{array}$ \\
\hline Number of Births & $\begin{array}{c}1.000001 \\
(19.560)\end{array}$ & $\begin{array}{c}1 \\
(2.774)\end{array}$ & $\begin{array}{c}1 \\
(2.601)\end{array}$ \\
\hline Population density in state & $\begin{array}{c}.99897 \\
(18.601)\end{array}$ & $\begin{array}{c}.9994 \\
(11.806)\end{array}$ & $\begin{array}{c}.9994 \\
(12.083)\end{array}$ \\
\hline Unemployment rate & $\begin{array}{r}1.01715 \\
(7.537)\end{array}$ & $\begin{array}{c}1.028 \\
(12.913)\end{array}$ & $\begin{array}{l}1.02695 \\
(12.458)\end{array}$ \\
\hline Poverty rate & $\begin{array}{l}1.0076 \\
(8.224)\end{array}$ & $\begin{array}{l}1.0135 \\
(14.944)\end{array}$ & $\begin{array}{c}1.0135 \\
(14.983)\end{array}$ \\
\hline Per Capita Income & $\begin{array}{c}1.000046 \\
(11.520)\end{array}$ & $\begin{array}{c}1.00002 \\
(5.462)\end{array}$ & $\begin{array}{r}1.00002 \\
(5.050)\end{array}$ \\
\hline Per Capita Income Maintanence & $\begin{array}{l}1.0008 \\
(11.053)\end{array}$ & $\begin{array}{l}1.00122 \\
(18.418)\end{array}$ & $\begin{array}{c}1.0012 \\
(18.333)\end{array}$ \\
\hline Per Capita Unemployment Insurance Payments & $\begin{array}{l}1.0015 \\
(11.260)\end{array}$ & $\begin{array}{l}1.00048 \\
(3.938)\end{array}$ & $\begin{array}{l}1.0005 \\
(4.092)\end{array}$ \\
\hline $\begin{array}{l}\text { Per Capita Retirement Payments for those over } \\
\text { age } 65\end{array}$ & $\begin{array}{r}0.99995 \\
(5.743)\end{array}$ & $\begin{array}{c}0.9994 \\
(11.806)\end{array}$ & $\begin{array}{c}0.9998 \\
(22.750)\end{array}$ \\
\hline Pseudo $\mathrm{R}^{2}$ & .9979 & .9948 & .9948 \\
\hline Log Likelihood & -11352.0 & -30056.0 & -30056.0 \\
\hline Chi-Square & 10759744 & 11441296 & 11441296 \\
\hline Number of observations & 772 & 772 & 772 \\
\hline
\end{tabular}




\section{Appendix 1: Descriptions of the Variables}

Variable

Murders by Age

Number of abortions by residents during the

year in which people of that age were born

$/ 1000$

Total abortions during the year in which people of that age were born / 1000

Population by Age

Trend in Right-to-carry Law Prior to Adoption

Trend in Right-to-carry Law After Adoption

Execution Rate

Prison Population

Arrest Rate for Murder

Arrest Rate for Violent Crime

Per Capita Income

Per Capita Income Maintanence

Per Capita Unemployment Insurance Payments

Per Capita Retirement Payments for those over age 65

DENSITYM

Unemployment rate

Poverty rate

Demographics in percentage points

Black Males between 10 and 19

Black Females between 10 and 19

White Males between 10 and 19

White Females between 10 and 19

Other Males between 10 and 19

Other Females between 10 and 19

Black Males between 20 and 29

Black Females between 20 and 29

White Males between 20 and 29

White Females between 20 and 29

Other Males between 20 and 29

Other Females between 20 and 29

Black Males between 30 and 39

Black Females between 30 and 39

White Males between 30 and 39

White Females between 30 and 39

Other Males between 30 and 39

Other Females between 30 and 39

Black Males between 40 and 49

Black Females between 40 and 49

White Males between 40 and 49

White Females between 40 and 49

Other Males between 40 and 49

Other Females between 40 and 49

Black Males between 50 and 64

Black Females between 50 and 64

White Males between 50 and 64
Number of

Observations

25300

22899

19.21838

4.790294

90.96882

17.46216

25806

6.409388

$\begin{array}{rr}21318 & 188686 \\ 24684 & -2.653298\end{array}$

246840.4982175

$\begin{array}{lll}24618 & 0.0013425\end{array}$

24684

24046

12422.24

87.44581

39.4515

23936

24684

24684

24684

13205.14

171.66

24684

69.38513

462.8054

$24684 \quad 355.0179$

24684

24684

6.323351

13.4406

246840.9993206

$\begin{array}{lll}24684 & 0.9839709\end{array}$

$24684 \quad 6.505527$

$24684 \quad 6.194945$

246840.3772582

$24684 \quad 0.3654634$

$24684 \quad 0.9303967$

$24684 \quad 1.004483$

$24684 \quad 6.986535$

$24684 \quad 6.837559$

246840.3628983

$24684 \quad 0.3683684$

246840.7519101

246840.8589242

24684

6.733915

$24684 \quad 6.680307$

$24684 \quad 0.3240372$

$\begin{array}{lll}24684 & 0.3547771\end{array}$

$24684 \quad 0.5181344$

$24684 \quad 0.6079785$

$24684 \quad 5.222173$

$24684 \quad 5.231165$

246840.2287975

246840.2560106

246840.5162729

246840.6497512

24684

5.759943
23.35659

794118.4

4.797428

1.700013

0.0058472

18497.49

52.23739

20.43871

2441.787

67.84943

43.26116

677.0433

1373.6

2.095975

4.164055

1.065861

1.079099

1.550095

1.513848

0.7256493

0.7024149

0.9918959

1.167355

1.326268

1.358468

0.679991

0.6891299

0.8392992

0.9985347

1.199101

1.195371

0.6690303

0.7041483

0.6054983

0.7384162

1.18768

1.152778

0.5285893

0.5697794

0.6649751

0.8637472

1.037859
$4041 \quad 1.76 \mathrm{E}+07$

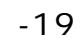

$0.7 \quad 11154$

$2.2 \quad 18$

$2.9 \quad 27.2$

$\begin{array}{ll}0 & 6.87\end{array}$

$0.02 \quad 7.08$

$0.73 \quad 10.18$

$0.70 \quad 9.91$

$0.03 \quad 5.9$

$0.03 \quad 5.71$

$0.04 \quad 6.57$

$0.02 \quad 7.73$

$2.48 \quad 10.85$

$1.89 \quad 9.66$

$0.03 \quad 5.33$

$0.04 \quad 5.55$

$0.02 \quad 5.28$

$0.01 \quad 6.11$

$2.45 \quad 9.88$

$2.29 \quad 9.44$

$0.03 \quad 5.44$

$0.03 \quad 5.54$

$0.01 \quad 4.08$

$0.01 \quad 5.06$

$1.34 \quad 8.579$

$1.2 \quad 8.59$

$0.02 \quad 4.97$

$0.02 \quad 5.23$

$0.008 \quad 4.79$

$0.008 \quad 6.1$

$1.61 \quad 8.12$ 
White Females between 50 and 64

Other Males between 50 and 64 Other Females between 50 and 64 Black Males 65 and older Black Females 65 and older White Males 65 and older White Females 65 and older Other Males 65 and older Other Females 65 and older

$\begin{array}{rrrrr}24684 & 6.160109 & 1.212295 & 1.4 & 8.71 \\ 24684 & 0.2104329 & 0.6049091 & 0.01 & 4.71 \\ 24684 & 0.2457903 & 0.697936 & 0.02 & 5.23 \\ 24684 & 0.361785 & 0.4881924 & 0.005 & 3.506 \\ 24684 & 0.5603818 & 0.8040356 & 0.005 & 6.16 \\ 24684 & 4.392195 & 1.162711 & 0.9 & 7.467 \\ 24684 & 6.370538 & 1.686248 & 0.92 & 9.98 \\ 24684 & 0.1346945 & 0.4977186 & 0.01 & 4.267 \\ 24684 & 0.1594036 & 0.5473673 & 0.01 & 5.339\end{array}$


Appendix 2: The Demographic and Age Dummy Coefficients for Specification 2 in Table 3 Variables

Incident Rate Standard $z$-statistic $P>|z|$ [95\% Conf. Interval] Ratio Error Coefficient

Demographics in percentage points Black Males between 10 and 19 Black Females between 10 and 19 White Males between 10 and 19 White Females between 10 and 19 Other Males between 10 and 19

Other Females between 10 and 19 Black Males between 20 and 29

Black Females between 20 and 29 White Males between 20 and 29 White Females between 20 and 29 Other Males between 20 and 29 Other Females between 20 and 29 Black Males between 30 and 39 Black Females between 30 and 39 White Males between 30 and 39 White Females between 30 and 39 Other Males between 30 and 39 Other Females between 30 and 39 Black Males between 40 and 49 Black Females between 40 and 49 White Males between 40 and 49 White Females between 40 and 49 Other Males between 40 and 49 Other Females between 40 and 49 Black Males between 50 and 64 Black Females between 50 and 64 White Males between 50 and 64 White Females between 50 and 64 Other Males between 50 and 64 Other Females between 50 and 64 Black Males 65 and older Black Females 65 and older White Males 65 and older White Females 65 and older Other Males 65 and older Other Females 65 and older Age Dummies

11 years old

12 years old

13 years old

14 years old

15 years old

16 years old

17 years old

$\begin{array}{lccccc}0.71 & 0.16 & -1.51 & 0.13 & 0.449 & 1.108 \\ 1.39 & 0.31 & 1.45 & 0.15 & 0.892 & 2.155 \\ 7.89 & 0.88 & 18.57 & 0.00 & 6.345 & 9.813 \\ 0.12 & 0.01 & -18.11 & 0.00 & 0.095 & 0.151 \\ 3.06 & 0.76 & 4.52 & 0.00 & 1.883 & 4.970 \\ 0.60 & 0.15 & -2.01 & 0.05 & 0.365 & 0.988 \\ 0.35 & 0.05 & -7.55 & 0.00 & 0.271 & 0.464 \\ 2.14 & 0.28 & 5.71 & 0.00 & 1.647 & 2.774 \\ 0.88 & 0.05 & -2.49 & 0.01 & 0.792 & 0.972 \\ 1.09 & 0.06 & 1.57 & 0.12 & 0.978 & 1.221 \\ 0.70 & 0.16 & -1.61 & 0.11 & 0.452 & 1.080 \\ 0.38 & 0.09 & -4.05 & 0.00 & 0.241 & 0.610 \\ 0.29 & 0.05 & -6.77 & 0.00 & 0.202 & 0.415 \\ 2.10 & 0.30 & 5.13 & 0.00 & 1.581 & 2.786 \\ 1.04 & 0.09 & 0.48 & 0.63 & 0.877 & 1.242 \\ 0.92 & 0.08 & -0.92 & 0.36 & 0.773 & 1.098 \\ 5.33 & 1.28 & 6.96 & 0.00 & 3.328 & 8.547 \\ 0.77 & 0.16 & -1.26 & 0.21 & 0.512 & 1.156 \\ 0.78 & 0.14 & -1.45 & 0.15 & 0.549 & 1.094 \\ 2.67 & 0.41 & 6.30 & 0.00 & 1.965 & 3.617 \\ 0.74 & 0.07 & -3.19 & 0.00 & 0.618 & 0.892 \\ 1.38 & 0.13 & 3.36 & 0.00 & 1.143 & 1.663 \\ 0.40 & 0.11 & -3.20 & 0.00 & 0.232 & 0.704 \\ 3.72 & 0.97 & 5.05 & 0.00 & 2.234 & 6.186 \\ 0.60 & 0.13 & -2.31 & 0.02 & 0.390 & 0.926 \\ 0.61 & 0.11 & -2.68 & 0.01 & 0.427 & 0.877 \\ 0.49 & 0.04 & -8.29 & 0.00 & 0.409 & 0.576 \\ 1.70 & 0.12 & 7.18 & 0.00 & 1.469 & 1.959 \\ 2.48 & 0.66 & 3.41 & 0.00 & 1.472 & 4.185 \\ 0.28 & 0.08 & -4.68 & 0.00 & 0.163 & 0.475 \\ 2.27 & 0.51 & 3.67 & 0.00 & 1.465 & 3.522 \\ 0.61 & 0.09 & -3.23 & 0.00 & 0.456 & 0.825 \\ 0.87 & 0.07 & -1.78 & 0.08 & 0.745 & 1.014 \\ 0.86 & 0.05 & -2.74 & 0.01 & 0.774 & 0.958 \\ 0.20 & 0.07 & -4.54 & 0.00 & 0.097 & 0.396 \\ 0.77 & 0.21 & -0.97 & 0.33 & 0.459 & 1.301 \\ & & & & & \\ 1.97 & 0.31 & 4.39 & 0.00 & 1.456 & 2.673 \\ 4.67 & 0.65 & 11.08 & 0.00 & 3.555 & 6.132 \\ 13.08 & 1.71 & 19.65 & 0.00 & 10.120 & 16.903 \\ 36.53 & 4.67 & 28.16 & 0.00 & 28.436 & 46.926 \\ 83.54 & 10.59 & 34.90 & 0.00 & 65.158 & 107.108 \\ 146.57 & 18.54 & 39.44 & 0.00 & 114.389 & 187.792 \\ 212.01 & 26.78 & 42.40 & 0.00 & 165.509 & 271.574\end{array}$


18 years old 19 years old 20 years old 21 years old 22 years old 23 years old 24 years old 25 years old 26 years old 27 years old 28 years old 29 years old 30 years old Over 30 years old Unknown Age Category

$\begin{array}{cccccc}255.44 & 32.26 & 43.89 & 0.00 & 199.431 & 327.177 \\ 263.92 & 33.33 & 44.15 & 0.00 & 206.052 & 338.039 \\ 275.46 & 34.79 & 44.49 & 0.00 & 215.059 & 352.813 \\ 226.90 & 28.67 & 42.93 & 0.00 & 177.128 & 290.657 \\ 219.66 & 27.76 & 42.67 & 0.00 & 171.473 & 281.400 \\ 208.78 & 26.39 & 42.26 & 0.00 & 162.968 & 267.470 \\ 193.85 & 24.51 & 41.66 & 0.00 & 151.300 & 248.355 \\ 207.82 & 26.27 & 42.22 & 0.00 & 162.213 & 266.251 \\ 169.83 & 21.48 & 40.59 & 0.00 & 132.536 & 217.612 \\ 163.34 & 20.67 & 40.28 & 0.00 & 127.466 & 209.305 \\ 157.01 & 19.87 & 39.96 & 0.00 & 122.521 & 201.204 \\ 145.69 & 18.44 & 39.36 & 0.00 & 113.678 & 186.708 \\ 158.54 & 20.06 & 40.04 & 0.00 & 123.715 & 203.163 \\ 2038.37 & 257.20 & 60.39 & 0.00 & 1591.759 & 2610.278 \\ 3.26 \mathrm{E}-24 & 4.4 \mathrm{E}-24 & -39.97 & 0.00 & 0.000 & 0.000\end{array}$




\section{Appendix 3: Additional Permutations of Table 3: Using the Supplemental Homicide Reports' method of distributing unknown murderers and excluding murders where the age of the criminal is unknown (Coefficients are Incident Rate Ratios, with absolute z-statistics reported in parentheses. The other variables that were included in the specifications were not reported here.)}

Number of murderers by age by state by year

In Terms of the Variables Accounted for in Each Specification the Columns Correspond to the Columns in Table 3

Variable 2

45

1) Using the Supplemental Homicide Reports' method of distributing the unknown murderers based on the known distribution by age/race/sex of offenders by state and year

Number of abortions during the year in which $\quad \begin{array}{llll}1.00029 & 1.00023 & 1.00023 & 1.00024\end{array}$

people of that age were born $/ 1000$

(72.763)

(47.823)

(47.248)

(48.362)

Dummy Variable for whether abortions are legal in a state

$\begin{array}{cccc}\ldots & & & \\ & \ldots & \ldots & \ldots \\ \text { unknow } & & & \\ 1.000230 & 1.000227 & 1.00023 & 1.00023 \\ (40.717) & (31.871) & (32.495) & (32.114)\end{array}$

$\ln$ (Number of abortions during the year in which people of that age were born /1000)

2) Exclude murders where the age of the criminal is unknow

Number of abortions during the year in which 1.000230

people of that age were born $/ 1000$

$(40.717)$

(31.871)

$(32.495)$

(32.114)

Dummy Variable for whether abortions are legal in a state
. .

\begin{tabular}{cccc} 
& \multicolumn{3}{l}{} \\
$\ldots$ & $\ldots$ & $\ldots$ & $\ldots$ \\
trend that is non-zero for the unknown age categor \\
1.0023 & 1.0018 & 1.0019 & 1.0019 \\
$(40.813)$ & $(26.812)$ & $(27.089)$ & $(27.245)$
\end{tabular}
(26.812)
(27.089)
$(27.245)$

1.081

(10.874)

(11.741)

(77.128)

$\ln$ (Number of abortions during the year in which people of that age were born /1000)

people of that age were born /1000

(40.813)

in a state

1.073

(9.923)

$\ln$ (Number of abortions during the year in which people of that age were born /1000)

3 ) Redoing Table 3 but replacing the linear trend state trend that 